Rodrigo Garcia Vilardi

Redução da Insegurança Pública: Política Pública de Segurança ou Política de Segurança Pública. Estudo de caso

Dissertação de Mestrado

Orientadora:

Professora Doutora Janaina Conceição Paschoal

UNIVERSIDADE DE SÃO PAULO

FACULDADE DE DIREITO

SÃO PAULO

2010 
Rodrigo Garcia Vilardi

\title{
Redução da Insegurança Pública: Política Pública de Segurança ou Política de Segurança Pública. Estudo de caso
}

\author{
Dissertação apresentada à Faculdade de \\ Direito da Universidade de São Paulo como \\ exigência parcial para obtenção do título de \\ Mestre em Direito Penal, sob orientação da \\ Professora Doutora Janaina Conceição \\ Paschoal
}

UNIVERSIDADE DE SÃO PAULO

FACULDADE DE DIREITO

SÃO PAULO

2010 


\section{INTRODUCÃ̃O}

É incontestável o fato de que a segurança pública, em âmbito local e nacional, apresenta inúmeros e consideráveis problemas, de tal forma que as expressões "caos" e "níveis insuportáveis" são freqüentemente utilizadas para defini-la.

José Eduardo Faria indaga: "se a segurança dos cidadãos é o sentido da existência do Estado, conforme dizia Hobbes, de que modo encará-lo à luz da atual realidade sócioeconômica brasileira, marcada por índices crescentes de violência?"1

Diante dessa circunstância, é muito comum a busca pela identificação das causas e conseqüente responsabilidade pelos problemas relacionados ao crime. Esta busca mostra-se tão sensível aos integrantes do corpo social que não seria exagero compará-la ao sentimento encontrado nos povos primitivos os quais, ante a ocorrência de um delito ou a qualquer infringência aos totens e tabus - suas regras de convivência - buscavam imputar o fato a algo ou a alguém, independentemente de qualquer culpa, apenas para que a "fúria dos deuses" fosse aplacada e suas conseqüências não recaíssem sobre toda a tribo. Este sentimento, normalmente intitulado sob o signo de "responsabilidade flutuante", reservadas as devidas peculiaridades, pode ser facilmente detectado hoje nos freqüentes debates atinentes ao fenômeno criminal, em especial nos meios midiáticos que, em geral, refletem os anseios e receios do cidadão comum.

Refletindo sobre o assunto, Janaina Conceição Paschoal ${ }^{3}$ aponta que basta a ocorrência de um delito com uma freqüência maior ou que atinja classes sociais mais privilegiadas, para que se iniciem as lutas para o aumento das medidas repressivo-penais, seja no sentido de duração das penas, seja no sentido de restrição de garantias, especialmente no que se refere às questões processuais-penais. No tocante às instituições policiais, suscita-se aumento do contingente ou ampliação do poder de polícia para outras

\footnotetext{
1 José Eduardo Faria em prefácio de Theodomiro Dias Neto. Segurança urbana: o modelo da nova prevenção. São Paulo: Revista dos Tribunais, 2005, p. 7.

2 Ante a uma ofensa às condições existenciais da sociedade, para os povos primitivos, seria necessária a punição de alguém, o criminoso ou outro em seu lugar, por meio de humilhação, desprezo ou expulsão do grupo, o que significaria a destruição simbólica do crime e conseqüente libertação do clã da impureza que o contaminou. A nomenclatura "responsabilidade flutuante" decorre da idéia de que a culpa pairava, flutuava sobre a tribo até encontrar algo ou alguém em quem recair sob a forma de punição.

${ }^{3}$ Janaina Conceição Paschoal. Segurança pública: poder e dever de todos. In: ILANUD (Org.). Das políticas de segurança pública às políticas públicas de segurança. São Paulo: ILANUD, 2002, p. 63.
} 
instituições, sem que haja a preocupação em se definir em que, realmente, esse poder consiste.

Direcionam-se, assim, os esforços única e exclusivamente aos efeitos e não às causas do problema, acarretando inflação legislativo-penal que derruba a sistemática do ordenamento jurídico e afasta, cada vez mais, os tipos penais dos princípios e garantias estabelecidos na Parte Geral do Código Penal.

Assim, ante a ocorrência de um fato grave e relevante relacionado à questão da segurança pública, inicia-se uma avalanche de discussões, na maioria das vezes, de modo superficial $^{4}$ e fragmentado, o que, geralmente, resulta na adoção de medidas tópicas e paliativas que, com o passar do tempo, se demonstram ineficazes ou insuficientes para a solução ou redução dos problemas.

Não tarda para que os problemas voltem a despontar. Nesse contexto, o calor dos acontecimentos aliado à necessidade de "pronta resposta", funciona como obstáculo a reflexões profundas sobre a questão, implicando, mais uma vez, em medidas inócuas.

Em que pese a complexidade do assunto, a obtenção de resultados ou soluções satisfatórias, isto é, a identificação de meios eficientes de redução dos problemas na área da segurança pública, será possível somente se, antes que se discutam os meios de combate mais eficazes, seja realizada uma análise que estabeleça pressupostos e/ou critérios mínimos para se tentar responder a algumas questões preliminares tais como: qual o conceito ou o que é segurança pública? Como mensurar ou identificar seus níveis? Quem são os responsáveis pela garantia deste direito e quais as respectivas parcelas de responsabilidade? Quais as causas ou condicionantes dos problemas ou, por assim dizer, da insegurança pública?

\footnotetext{
${ }^{4}$ Apenas a título exemplificativo, cite-se a conclusão apontada por João Gonçalves de Lemos que em artigo sobre segurança pública afirma que "das leituras dos jornais, revistas, enfim, nos diversos meios de comunicação social, conclui-se que a segurança pública não pode continuar como se acha presentemente (...) pelo menos três aspectos devem ser examinados: a Constituição Federal não deve se imiscuir com segurança pública; a polícia é uma atividade essencialmente civil e não deve existir uma Justiça especial militar" (João Gonçalves de Lemos. Segurança pública: direito do cidadão x obrigação do estado. In: César Barros Leal; Heitor Piedade Júnior (Orgs.). Violência e vitimização: a face sombria do cotidiano. Belo Horizonte: Del Rey, 2001, p. 154.). Esta conclusão não é acompanhada, no artigo, de nenhuma análise ou argumento que dê algum tipo de lastro ao raciocínio do autor, derivando apenas de suas concepções ideológicas. Infelizmente, esta superficialidade nas reflexões sobre o tema é freqüente e, com certeza, é corroborada pela fragilidade que será demonstrada - dos estudos sobre a eficiência das ações desenvolvidas nesta área. A idéia é simples: se não existem estudos que comprovem o que funciona, escolhe-se a opção a ser defendida e difundida com base apenas em concepções subjetivas.
} 
As respostas a tais questionamentos fornecerão uma percepção global e interdisciplinar do assunto, de modo a facilitar a busca pelos meios mais aptos a proporcionar melhorias nesta área.

No que se refere à necessidade de conceituação e determinação dos modos de mensuração da segurança pública, de se ver que se tratam dos pressupostos ou critérios básicos para a análise da eficácia dos meios de redução da insegurança, pois, somente se poderá compreender se houve alguma alteração neste aspecto, a partir do momento em que seja possível definir o que é, na realidade, a segurança pública e como avaliar seu nível ${ }^{5}$. Sendo assim, tais respostas antecedem o foco principal de qualquer estudo sobre o tema.

Já no que diz respeito aos outros questionamentos, relativos à responsabilidade e às causas da insegurança pública, as reflexões não se apresentam, de modo tão nítido, como pressuposto para a identificação dos meios mais apropriados à melhora do quadro atual. A análise da responsabilidade confunde-se, muitas vezes, com a própria identificação das causas e ambas, normalmente, só serão passíveis de compreensão após a implementação de experiências práticas na tentativa de redução dos fatores condicionantes da criminalidade.

Entretanto, tais dificuldades e o entrelaçamento dos tópicos não afastam a necessidade de uma análise prévia sobre as responsabilidades e complexidade dos fatores geradores das práticas de infrações penais. Somente com esta reflexão, ainda que ampla e sem delimitações precisas, será possível selecionar algumas hipóteses para definição dos meios de enfrentamento do problema, em tese, mais adequados.

No exame sobre a responsabilidade pelas deficiências existentes na segurança pública, é comum a conclusão de que todos os problemas devem ser imputados às autoridades públicas.

Como afirma Janaina Conceição Paschoal ${ }^{6}$, é freqüente a cobrança por soluções em face do Poder Público. Cobra-se do Poder Executivo, sem que haja reflexão acerca dos limites orçamentários e avaliações sobre eficiências das medidas pleiteadas, como aumento de efetivo policial, compra de equipamentos e assim por diante. No âmbito do Poder Legislativo, os reclamos recaem sobre edição de leis mais severas e que afastem regras

\footnotetext{
5 Não que tais questões estejam sedimentadas nos inúmeros trabalhos sobre o tema, entretanto, será necessário analisar os conceitos e critérios até então adotados e selecionar alguns destes para utilização como instrumento de trabalho.

${ }^{6}$ Janaina Conceição Paschoal. Segurança pública: poder e dever de todos. In: ILANUD (Org.). Das políticas de segurança pública às políticas públicas de segurança. São Paulo: ILANUD, 2002, p. 63.
} 
garantistas que foram conquistadas em decorrência de abusos estatais. Finalmente, do Poder Judiciário, espera-se sempre a concessão incondicional de medidas cautelares que restrinjam a liberdade dos acusados e a aplicação de penas nos máximos legais, independentemente da análise dos parâmetros normativos referentes à dosimetria da sanção.

Por óbvio que o Estado, por meio de seus poderes constituídos, possui considerável parcela de responsabilidade, até porque a própria Constituição Federal prevê que a questão é seu "dever" e, provavelmente, a sua razão de existência mais remota. Não obstante, as autoridades públicas, pressionadas pelos anseios populares, apesar de assumirem parcelas inafastáveis desta missão, recorrem, repetidamente, ao mesmo caput do artigo 144 da Constituição Federal para ressaltar que a segurança pública também é "responsabilidade de todos". Referido artigo acaba, por vezes, sendo utilizado como "uma tábua de salvação" pelos agentes públicos, pois divide o fardo da responsabilidade com todos os integrantes do corpo social.

Decerto que a responsabilidade deve ser compartilhada, até mesmo por previsão normativa, mas as questões que ainda não estão bem definidas são: de que modo compartilhá-la? Na questão da segurança pública, quais os deveres e limites de atuação dos órgãos próprios do sistema ${ }^{7}$, dos demais órgãos governamentais ${ }^{8}$ e da sociedade? $\mathrm{E}$ como a sociedade deve assumir a responsabilidade? Por meio de atos particulares, simplesmente, participando de atividades comunitárias (tais como associações de bairros ${ }^{9}$ ) ou, assumindo um papel mais amplo, participando de entidades privadas, sem fins lucrativos, que, atualmente, desenvolvem projetos em regiões especialmente atingidas pela criminalidade ${ }^{10}$ ? As respostas a tais questionamentos, ou seja, um mínimo de clareza sobre o papel que cada um desenvolve nesta questão é essencial para o alcance de dois objetivos: (i) a atenuação de cobranças indevidas ou ilegítimas em face do Estado com a conseqüente

\footnotetext{
${ }^{7}$ Recentemente, o problema da segurança pública tem sido abordado não apenas como responsabilidade do governo estadual e do sistema de justiça criminal, mas como responsabilidade de todas as esferas e setores do Estado (vide: Túlio Kahn; André Zanetic. O papel dos municípios na segurança pública. Estudos Criminológicos, São Paulo: Secretaria de Estado dos Negócios da Segurança Pública, n. 4, 2005, p. 3).

${ }^{8}$ Ou seja, de que modo órgãos governamentais que não compõem o sistema de segurança pública possuem responsabilidade pela questão?

${ }^{9}$ A exemplo do que ocorre, desde 1984, no estado de São Paulo com os Conselhos de Segurança de Bairros CONSEGs - cujas funções serão abordadas neste trabalho.

${ }^{10}$ Como exemplo: Unidade Comunitária de Álcool e Drogas e Sociedade Santos Mártires que são entidades comunitárias que atuam no distrito do Jardim Ângela (São Paulo/SP), auxiliando comunidades carentes, pessoas que apresentam dependência do álcool, ou, ainda, Sociedade Beneficente Caminhando para o Futuro que atua no distrito de Brasilândia (São Paulo/SP).
} 
conscientização do cidadão acerca de suas próprias responsabilidades ${ }^{11}$ e (ii) a identificação das medidas que estão ao alcance do Poder Público, de modo que as cobranças possam ser mais objetivas e redundar em ações eficientes.

Esta distinção não tem por objetivo defender a idéia de que o Estado não deve ser cobrado pela sua parcela de atuação. Ora, como já dito, propiciar condições de segurança é um de seus principais fundamentos de legitimação. Na verdade, na reflexão sobre suas limitações, o verdadeiro intuito é a busca de respostas efetivas ao problema da insegurança pública para que não se recaia em um simples "denuncismo" que pode até gerar mudanças positivas na atuação estatal, mas não enfrentará o problema em sua totalidade e complexidade.

Ao lado desta discussão sobre a demarcação das responsabilidades e entremeandoa, colocam-se as reflexões acerca das causas da insegurança pública, ou seja, quais as principais matrizes dos problemas existentes.

Neste aspecto, de extrema pertinência a observação de Luiz Eduardo Soares no sentido de que não há facilidade nas explicações para a violência e para o crime, pois este não existe no singular. Há uma diversidade nas práticas criminosas que decorrem de dinâmicas sociais díspares, não sendo possível, por tal motivo, a identificação de apenas "uma causa para o universo heterogêneo da criminalidade" 12 .

Dentre estas dinâmicas sociais como condicionantes da criminalidade, pode-se citar, de modo apenas ilustrativo, conflitos interpessoais, crime organizado, corrupção do Poder Público como meio facilitador do livre fluxo da prática delitual, lavagem de dinheiro, estruturas para receptação dos produtos derivados da prática do crime, disponibilidade de armas legais e ilegais, baixos índices de esclarecimentos de crimes, morosidade na aplicação da lei penal, deficiências estruturais no sistema prisional, na fiscalização de medidas não privativas de liberdade, no abandono do egresso e, em especial, as deficiências no sistema educacional, desigualdade social e o tráfico ilícito de entorpecentes - por possuir alto poder de infiltração cultural e econômica, trazendo, por

\footnotetext{
11 Theodomiro Dias Neto, em dissertação de Mestrado defendida em 1992, na Faculdade de Direito de Wisconsin (Madison, EUA), citando um trabalho científico realizado por um instituto de justiça dos EUA, afirma que o contato entre polícia e comunidade contribui para a compreensão das limitações do poder público e a necessidade de se compartilhar ações para resolução dos complexos problemas (Theodomiro Dias Neto. Policiamento comunitário e controle sobre a polícia: a experiência norte-americana. São Paulo: IBCCrim, 2000, p. 60-2.).

${ }^{12}$ Luiz Eduardo Soares. Segurança pública: presente e futuro. Estudos Avançados, São Paulo: ScieloBrazil, v. 20, n. 56, jan.-abr. 2006, p. 93.
} 
conseguinte, promessas de status e carreira promissora aos jovens dos mais baixos níveis sócio-econômicos.

Logicamente, tanto a análise das origens e causas, quanto à divisão das responsabilidades, conduz diretamente aos meios de redução dos problemas relacionados à área de segurança pública, vez que todos os debates acerca do assunto são travados com esta finalidade, ou seja, todos os estudos sobre o motivo pelo qual a segurança pública se encontra em crise e quais os responsáveis pelas soluções, têm como objetivo último identificar modos para que se afaste a atual situação ${ }^{13}$.

Sendo assim, na presente proposta de estudo, todas as reflexões anteriormente citadas $^{14}$, serão realizadas de modo subjacente e subsidiária ao foco central do tema, que pode ser sintetizado em duas questões: (i) quais os meios de redução da insegurança pública? (ii) quais os modos mais eficientes de implementá-los?

As alternativas de respostas a estas questões foram e são alvo de inúmeros estudos e implementações por ações governamentais ${ }^{15}$, não governamentais ${ }^{16}$ e até acadêmicas ${ }^{17}$, sob a forma de programas, seminários, artigos, teses ou planos de segurança, etc.

Dentre elas, inúmeros sucessos e avanços podem e merecem ser estudados, contudo, há ainda um dilema ou, por melhor dizer, ponto nevrálgico, que, ao menos aparentemente, não foi enfrentado de modo conclusivo em tais experiências. Não que o tema suporte conclusões ou abordagens exaustivas, mas, nesta questão, parece existir, ainda, preconceitos e acepções carregadas de conteúdo ideológico.

\footnotetext{
${ }^{13}$ Neste sentido: "O verdadeiro objetivo da ciência é beneficiar o homem. Uma ciência que não consegue isso, por mais agradável que seja seu estudo, carece de vida, de utilidade” (João Gaspar Rodrigues. Segurança Pública e Comunidade. Porto Alegre: Sergio Antonio Fabris Editor, 2009, p. 21).

${ }^{14}$ Conceito, modos de mensuração, causas e responsabilidade.

${ }^{15}$ Como exemplos: no âmbito da União, criação da Secretaria Nacional de Segurança Pública, em 1997, e decorrente criação do Plano Nacional de Segurança Pública e Fundo Nacional de Segurança Pública; no estado de São Paulo, a implementação da filosofia do policiamento comunitário no âmbito da Polícia Militar e da "delegacia participativa" e, no âmbito da Polícia Civil, o incentivo aos Conselhos de Seguranças (CONSEGs); no município de São Paulo, a criação da Coordenadoria de Segurança Urbana, em 2005, e investimento na estrutura da Guarda Civil Metropolitana.

${ }^{16}$ Como exemplos: Criação da Instituição "Viva Rio" no Rio de Janeiro (1993); criação dos Institutos "São Paulo contra a Violência" (1997) e "Sou da Paz" (1999) em São Paulo.

17 V.g. o Núcleo de Estudos da Violência (NEV-1987) - centro de pesquisa vinculado à pró-reitoria da Universidade de São Paulo -, Centro de Estudos Sociais e Contemporâneos (CESEC) da Universidade Cândido Mendes, no Rio de Janeiro e o Centro de Estudos de Criminalidade e Segurança Pública (CRISP) da UFMG, em Minas Gerais.
} 
O dilema reside no ponto em que se discute se o problema da segurança pública deve ser enfrentado nas suas causas ou nos seus efeitos, ou, ainda, priorizando-se as medidas ditas "preventivas" ou "repressivas".

Este "dilema" foi muito bem destacado, ainda que sob distintos enfoques, por Luiz Eduardo Soares e Ana Sofia Schmidt de Oliveira.

De acordo com o primeiro, é muito comum a dúvida em se combater as causas da criminalidade ou a própria criminalidade o que normalmente induz ao imobilismo, tendo em vista que as grandes iniqüidades estruturais da sociedade brasileira impediriam qualquer medida que visasse diminuir o atual estado de insegurança. Deste modo, sob esta perspectiva, "ou se faz tudo, ou nada resta a fazer; ou se alteram as causas profundas e permanentes, ou estaríamos condenados a enxugar gelo"18.

No mesmo sentido, mas sob outro enfoque, Ana Sofia Schmidt de Oliveira destaca que nas discussões acerca do problema da segurança pública, apesar da noção já sedimentada de que o problema é de todos, ainda se observa, freqüentemente, a armadilha do efeito gangorra entre o "discurso social" e o "discurso repressivo", vendo-se, em regra, ambos os discursos como excludentes.

Esta dicotomia - no sentido frisado pela autora de dois conceitos opostos que esgotam o conteúdo de um tema - entre prevenção e repressão, decorrente das crenças que dominam a percepção do problema, funciona como pano de fundo para o paradigma de que as políticas de segurança ou são repressivas (e independentes das macro políticas) ou são preventivas (subordinadas, portanto, à alteração do quadro social). Diante disso, conclui pela dificuldade de fugir da dicotomia, do antagonismo. ${ }^{19}$

Ambos os autores não se limitam a apontar o "dilema" e indicam possíveis soluções. Luiz Eduardo Soares $^{20}$ enfatiza que experiências nacionais e internacionais já demonstraram a possibilidade de se combinar ações públicas de natureza preventiva que, mesmo sem ter atuado sobre as causas estruturais, apresentaram resultados concretos em espaços relativamente curtos de tempo e, mesmo que tenham incidido, em um primeiro momento de modo superficial sobre o problema, salvaram vidas e reduziram danos. Em

\footnotetext{
${ }^{18}$ Luiz Eduardo Soares. Segurança pública: presente e futuro. Estudos Avançados, São Paulo: ScieloBrazil, v. 20, n. 56, jan.-abr. 2006, p. 94.

${ }^{19}$ Ana Sofia Schmidt de Oliveira. Políticas públicas de segurança e políticas de segurança pública: da teoria a prática. In: ILANUD (Org.). Das políticas de segurança pública às políticas públicas de segurança. São Paulo, 2002, p. 46-7.

${ }^{20}$ Luiz Eduardo Soares. Op. cit., loc. cit.
} 
muitos casos, tiveram o condão de suscitar sentimentos e percepções coletivas que alteraram um quadro local de insegurança pública e criaram "situações menos permeáveis às pressões dos fatores criminógenos" sintomas podem matar o paciente e devem ser tratados, enquanto o paciente não está pronto para a cirurgia. Até porque, sem tratá-los, a cirurgia não será possível”22.

Já Ana Sofia Schmidt de Oliveira entende que para um bom equacionamento da questão, a fim de torná-la produtiva, fugindo-se da tentação e do comodismo dos discursos excludentes e superficiais, é necessário estabelecer a distinção entre políticas de segurança pública e políticas públicas de segurança.

$\mathrm{Na}$ visão desta autora, politicas de segurança pública é expressão referente às atividades tipicamente policiais, ou seja, "é a atuação policial 'strictu sensu",23. Por outro lado, políticas públicas de segurança "é expressão que engloba as diversas ações, governamentais e não governamentais, que sofrem impacto ou causam impacto no problema da criminalidade e da violência"24. Assim, ambas podem e devem ser implementadas de maneira concomitante para uma efetiva melhoria na questão da segurança pública.

Nesta diferenciação apresentada pela autora, as políticas públicas de segurança que se concretizam por meio de ações de cunho social dificilmente são contestadas por qualquer segmento da sociedade, vez que, ao menos na visão ideal, não geram efeitos negativos sobre nenhum dos integrantes do corpo social. $\mathrm{O}$ mesmo não se pode dizer das políticas de segurança pública que, muitas vezes, são imaginadas apenas sobre o aspecto repressivo, o que não condiz com a realidade.

Neste trabalho, após a análise crítica da distinção conceitual apresentada por Ana Sofia Schmidt de Oliveira e a apresentação de uma proposta, não antagônica, mas sob outra perspectiva, serão debatidas políticas de segurança pública que mesclam atividades preventivas e repressivas na busca pela prevenção criminal e redução do "medo do crime".

\footnotetext{
${ }^{21}$ Luiz Eduardo Soares. Segurança pública: presente e futuro. Estudos Avançados, São Paulo: ScieloBrazil, v. 20, n. 56, jan.-abr. 2006, p. 95.

${ }^{22}$ Idem, ibidem, loc. cit.

${ }^{23}$ Ana Sofia Schmidt de Oliveira. Políticas públicas de segurança e políticas de segurança pública: da teoria a prática. In: ILANUD (Org.). Das políticas de segurança pública às políticas públicas de segurança. São Paulo, 2002, p. 47.

${ }^{24}$ Idem, ibidem, loc.cit.
} 
Especialmente no que diz respeito às medidas repressivas, diretamente relacionadas à persecução penal como meio de redução da insegurança pública, as experiências apresentadas buscarão demonstrar que, respeitadas as limitações fáticas ${ }^{25}$ e jurídicas, poderão ser obtidos resultados positivos.

Apesar de não haver dúvidas de que o Direito Penal, per si, não é capaz de solucionar os problemas atinentes à segurança pública e evitar o cometimento de delitos ${ }^{26}$, nos meios acadêmicos em especial, a repulsa, ainda que justificada, pela freqüente eleição do endurecimento das leis como panacéia da segurança pública, por vezes, pode afastar uma análise de experiências interessantes em que a persecução penal, como resposta aos problemas relacionados a esta área, não foi apresentado por meio de recrudescimento das penas, mas sim de sua simples aplicação.

Neste sentido, pode-se citar que o aumento da taxa de encarceramento de homicidas $^{27}$ e o aumento na média de esclarecimento de casos pelo Departamento de Homicídios e de Proteção à Pessoa da Polícia Civil no Estado de São Paulo ${ }^{28}$ já foram indicados como algumas das prováveis hipóteses para a redução desse tipo de crime no estado de São Paulo.

25 No âmbito internacional, Marcos Rolim, analisando a relação entre crimes notificados e pessoas sentenciadas, advertidas ou multadas na Inglaterra e no País de Gales em 2000, verifica que, apesar dos 5 milhões de crimes registrados pelas polícias, apenas $350 \mathrm{mil}$ pessoas foram sentenciadas e 151 mil advertidas ou multadas, demonstrando que apenas um em cada 10 crimes registrados resulta em alguma sanção (Marcos Rolim. A Síndrome da Rainha Vermelha: policiamento e segurança pública no século XXI. 2 ed. Rio de Janeiro: Jorge Zahar, 2009, p. 58). No mesmo sentido, Julita Lemgruber examina algumas crenças relativas ao sistema de justiça criminal e indica levantamento realizado na Inglaterra e País de Gales em 1997 em que se constatou que em cada 100 crimes cometidos naquele ano, 45,2 foram comunicados à polícia, 24 foram registrados, 5,5 foram esclarecidos, 2,2 resultaram em condenação e, apenas, 0,3 resultou em pena de prisão (Julita Lemgruber. Verdades e mentiras sobre o sistema de justiça criminal. Revista Centro de Estudos Judiciários, Brasília: Conselho da Justiça Federal, n. 15, set.-dez. 2001, p. 13. Disponível em: $<$ http://www2.cjf.jus.br/ojs2/index.php/cej/article/viewFile/427/608>. Acesso em: 29.11.2009.). No âmbito nacional, Túlio Kahn, com base em dados extraídos da Secretaria de Estado dos Negócios da Segurança Pública de São Paulo, relativos ao segundo trimestre de 2006, fornece uma noção da taxa de atrito no estado ao identificar que, naquele período, foram notificados pela polícia 489.202 crimes, podendo-se estimar, de acordo com pesquisas de vitimização realizadas pela mesma Secretaria, a ocorrência de 931.813 crimes no estado. Apesar deste montante, somente 74.880 inquéritos policiais foram instaurados ( $8 \%$ do total de crimes estimados), sendo que 23.535 pessoas foram presas em flagrante delito ( $2,5 \%$ do total de crimes estimados) e dessas, apenas, 3.000 permaneceram presas $(0,3 \%$ do total de crimes estimados) (Túlio Kahn. Defesa nacional e segurança pública. In: Segurança e Defesa Nacional: da competição à cooperação regional. São Paulo: Fundação Memorial da América latina, out. 2006. Disponível em: $<$ http://www.memorial.sp.gov.br/memorial/RssNoticiaDetalhe.do?noticiaId=788>. Acesso em: 29.11.2009).

${ }^{26}$ Até mesmo em programas televisivos que angariam sua audiência com a veiculação reiterada e alarmante de crimes, já é possível detectar, ainda que de modo subjacente e intercalado às cobranças por punições e leis mais severas, menções a outros problemas, em especial aos relativos à desigualdade sócio-econômica.

${ }^{27}$ Túlio Kahn. Homicídios dolosos em São Paulo. Estudos Criminológicos. São Paulo: Secretaria de Estado dos Negócios da Segurança Pública, n. 1, 2004, p. 23-24.

${ }^{28}$ Idem, ibidem, p. 26. 
Sendo assim, este é um aspecto que merece detido estudo: se, por um lado, os reais reflexos de uma alteração legislativa no âmbito penal são de difícil mensuração, por outro, o impacto de medidas relacionadas ao aumento de eficácia na persecução penal, em áreas restritas, pode e merece ser analisado para uma melhor compreensão dos efeitos deste na redução da insegurança pública.

Esta abordagem sobre as políticas públicas de segurança (PPS) e políticas de segurança pública (PSP), sob o ponto de vista conceitual e experimental, resulta na identificação de experiências que demonstram que, independentemente do combate às causas estruturais ou macroestruturais, que se opera de maneira lenta e gradual, iniciativas implementadas em âmbito local, com a implementação de políticas públicas preventivas e repressivas, especialmente no que diz respeito às políticas de segurança pública em virtude da distinção conceitual que será proposta, apresentaram resultados interessantes e frutíferos.

Entretanto, a simples identificação destas experiências e demonstração de resultados positivos, não seria suficiente para a resolução dos problemas na área de segurança pública. Como será abordado no capítulo 2 deste trabalho, as condicionantes criminais apresentam uma dinâmica que varia significativamente entre regiões, cidades, distritos e bairros (ou até mesmo em um mesmo bairro se considerado o transcurso do lapso temporal). Desta forma, além da identificação de políticas públicas eficientes na questão da segurança pública, é imprescindível a análise e reflexão acerca do caminho percorrido para o alcance destes resultados. Por mais que uma experiência tenha sido bem sucedida em um determinado lugar, por um tempo específico, isso não garante que ela continuará sendo bem conduzida neste mesmo lugar ou implementada de modo eficiente em outro.

Assim, posteriormente à distinção conceitual das políticas públicas e análise da eficiência por meio do estudo de caso realizado no segundo capítulo, o terceiro capítulo é destinado à discussão acerca de um modelo que garanta que os atributos de uma eficiente política de segurança pública, serão observados em qualquer região ou localidade. A idéia será identificar um modelo que garanta esta flexibilidade na seleção e adequação das políticas destinadas à redução da insegurança pública em relação aos princípios democráticos de direitos e características locais peculiares. A opção pela análise dos modelos de polícia está fundamentada na abordagem a ser realizada no capítulo 1 acerca da 
escolha constitucional no que diz respeito aos órgãos responsáveis pela prestação do serviço de segurança pública.

Assim, em suma, o objetivo do presente trabalho é buscar conceituar e delimitar o que é segurança pública, os responsáveis por garanti-la e como mensurá-la. A partir destes parâmetros conceituais, definir se o problema criminal deve ser enfocado pelas políticas públicas de segurança e/ou políticas de segurança pública e, em caso afirmativo, como deve ser esse enfoque, identificando-se, por fim, modelos estruturais que possuam os princípios e mecanismos necessários para a melhor aplicação destas políticas e, por conseqüência, a redução da atual situação de insegurança pública. 


\section{CONCLUSÃO}

O presente trabalho teve como objetivo analisar os meios de resolução ou melhora da situação da segurança pública no que diz respeito à sociedade brasileira.

Neste sentido, a primeira tarefa realizada foi a identificação de um conceito de segurança pública que possibilitasse a correta delimitação do objeto de estudo, não somente em nível teórico, mas com reflexos na relação entre este objeto, os instrumentos de intervenção postos à disposição do Estado para nele atuar e as instituições responsáveis por esta atividade estatal.

Segurança pública, em termos conceituais, após uma breve abordagem da evolução do seu significado no processo histórico e a comparação com as atuais visões acerca da questão, foi conceituada como "um estado de ausência ou risco iminente de ocorrência de infrações penais ou atos infracionais, e de percepção desta circunstância por parte dos integrantes da sociedade", sendo ressaltado, ainda, que ela, em conjunto com a tranqüilidade e salubridade pública, formam a tríade dos aspectos da ordem pública que é a situação de convivência social pacífica entre os cidadãos.

A limitação da segurança pública à questão penal não é casual. Considerando que o serviço de segurança pública tem à sua disposição instrumentos de intervenção de extrema gravidade no que diz respeito aos direitos fundamentais dos cidadãos, é importante que ela seja vinculada a fatos que demonstram relevância compatível com tais instrumentos.

Neste sentido, mesmo que uma instituição tenha como atribuição a manutenção da ordem pública, como é o caso da Polícia Militar, há de se distinguir quando se está atuando com questões diretamente relacionadas aos delitos (segurança pública) e quando atua com questões de menor gravidade (tranqüilidade e salubridade pública) oportunidade em que serão limitados também seus meios de intervenção.

No mesmo sentido, foi identificada a dupla natureza jurídica da segurança pública. A primeira como direito fundamental que integra em seu conteúdo, em regra, o total respeito aos demais direitos em razão de seu caráter instrumental, e a segunda como serviço público, que permite um melhor relacionamento com os princípios democráticos de direito e controle pelo Poder Judiciário, além de ressaltar seu caráter de prestação positiva, no sentido de concretização de atos com o objetivo de garantir o direito à segurança 
pública dos integrantes da sociedade e não apenas atuar para posterior responsabilização penal.

Esta dupla natureza jurídica, de direito fundamental e serviço público, auxilia na compreensão de que se os cidadãos possuem direito a um "estado de ausência ou risco iminente de ocorrência de infrações penais ou atos infracionais e de percepção desta circunstância”, ainda que este esteja longe de se concretizar, e assim esteja caracterizada a situação de insegurança pública, cabe aos responsáveis pelo serviço de segurança pública a busca no sentido de concretização deste direito.

Definido o conceito e a natureza jurídica, passou-se à análise da responsabilidade constitucional pela garantia deste direito e respectivos meios de mensuração. Na questão da responsabilidade foi verificado que, apesar da Constituição Federal, em seu artigo 144, disciplinar que ela é "responsabilidade de todos", desta previsão não decorre, em regra, obrigações jurídicas aos particulares. Estes, afora a responsabilização penal pela prática de delitos, só serão obrigados a determinadas ações ou omissões, ou seja, terão responsabilidade pela questão da segurança pública, se incrementarem o risco de ocorrência de infrações penais ou se estiverem em alguma condição específica frente aos delitos praticados. De todo modo, as obrigações deverão advir sempre de lei. Nos demais casos, caberá aos particulares o pleno exercício da cidadania e conseqüente aperfeiçoamento dos controles sociais informais e fomento do "capital social", não como obrigação, mas como direito.

O mesmo não ocorre ao se analisar o dever e a responsabilidade do Estado em relação a tal questão. O dever imposto ao Estado recai precipuamente sobre as instituições policiais elencadas no artigo 144 da Constituição Federal que estruturam o sistema de segurança pública brasileiro. Por tal motivo, mesmo em problemas relacionados à segurança pública que não estejam na esfera de atuação dos órgãos policiais, caberá a estes a busca pela coordenação com outros setores para que o serviço público seja concretizado da melhor maneira possível. Quanto aos demais órgãos públicos, não integrantes do sistema de segurança pública, competem-lhes o exercício de suas funções constitucionais originárias, visto que a ótima prestação dos demais serviços públicos atenuará os fatores de risco e contribuirão com as condições propícias à garantia deste direito. Nos casos em que sejam convidados a colaborar com ações destinadas à prevenção criminal, deverão contribuir em virtude desta ser "responsabilidade de todos". Contudo, 
esta contribuição não deverá prejudicar suas funções originárias nem desrespeitar suas atribuições legais e constitucionais.

Ainda no que diz respeito ao dever do Estado em prestar o serviço de segurança pública, através da análise das atribuições constitucionais e, inclusive, da estrutura física das instituições, restou claro que, apesar do inegável progresso e imprescindível auxílio dos governos federal e municipal no trato da questão, qualquer iniciativa deve obrigatoriamente focar as instituições policiais estaduais que abarcam o maior espectro de atividades destinadas, quer à prevenção, quer à repressão qualificada das infrações penais, o que motivou a posterior opção pela análise dos modelos de policiamento que propiciassem melhores condições à implementação de políticas de segurança pública destinadas à redução da insegurança pública.

Outro ponto também tratado refere-se aos modos de aferição do nível de garantia do direito à segurança pública, pois, a inexistência de critérios de mensuração impossibilita análise quanto à eficiência dos meios de intervenção. Reconhecendo-se as limitações de cada método, pode-se atingir patamares razoáveis de conhecimento acerca do problema por meio dos registros criminais e pesquisas de vitimização, atentando-se para a necessidade, cada vez maior, de padronização dos dados com a finalidade de que não se perpetue a fragmentação de esforços e iniciativas neste setor.

A definição conceitual, a responsabilidade e os modos de mensuração foram abordados em caráter subsidiário ao principal objetivo do trabalho, qual seja o de identificar meios de intervenção que atenuassem os problemas atualmente enfrentados nesta área.

O breve estudo sobre as condicionantes individuais e estruturais revelou que existem fatores relacionados às características pessoais, aos controles sociais informais e à estrutura da sociedade que fomentam matrizes criminais, seja pelas redes de organizações criminosas, seja em virtude da desigualdade social. Entretanto, a verificação feita neste estudo consiste na eficiência de políticas adotadas em âmbito local que, mesmo sem modificar substancialmente questões estruturais, impactam positivamente fatores relacionados ao crime, proporcionando, assim, melhora na qualidade de vida da população atingida.

Esta abordagem demonstrou-se não apenas como tendência verificável na área da segurança pública, mas, de modo geral, em todos os setores da Administração Pública em 
virtude da assunção cada vez maior da esfera municipal, e até mesmo distrital, na prestação dos serviços públicos, especialmente pela proximidade com os problemas a serem enfrentados.

A partir deste ponto e estabelecido o que se entende por políticas públicas, iniciaram-se os estudos das políticas em específico. No que diz respeito às políticas públicas de segurança ou, como estas vêm sendo implementadas, foi observado que apesar da ampla divulgação acerca dos resultados relacionados à prevenção criminal, pouco se demonstrou a este respeito.

Assim, embora estas políticas garantam o exercício de outros direitos fundamentais e, por conseqüência, devam provocar algum impacto positivo na área da segurança pública, constatou-se que as informações publicadas acerca dos projetos não se fundamentam em dados objetivos com relação ao fenômeno criminal nas áreas enfocadas. O estudo de caso referente ao projeto "Praças da Paz" também não apresentou resultados diferentes acerca da redução de delitos.

Por tal motivo, a fim de que os resultados proveitosos no sentido de garantia dos demais direitos não fossem menosprezados, nem tampouco, abandonadas medidas diretamente direcionadas à questão criminal, concluiu-se que as políticas públicas de segurança podem reduzir a prática de crimes e auxiliar na percepção sobre o sentimento de segurança, entretanto, esta não é sua finalidade, não podendo vincular-se a tais objetivos.

Deste modo, impedir-se-ia uma "colonização" indesejada das políticas sociais pela lógica da prevenção criminal, impedindo-se que os demais direitos fundamentais de classes menos favorecidas fosse garantido única e tão somente com o objetivo de se evitar a prática de delitos.

Em relação às políticas de segurança pública, optou-se pela ampliação conceitual, visto que não se resumem às atividades policiais strictu sensu, mas a todas as medidas, preventivas ou repressivas, particulares ou públicas, que tenham por foco a melhora na segurança pública (redução de delitos e sentimento de segurança).

Após cotejar a definição adotada com outras nomenclaturas utilizadas (v.g. nova prevenção, prevenção primária, secundária, terciária), apresentou-se o estudo de caso referente à videomonitorização, demonstrando-se a obtenção de resultados significativos em termos de redução de alguns delitos na maioria das áreas pesquisadas. 
Contudo, face à constatação de que em uma das áreas os resultados foram inversos às demais, aliada à necessidade de que medidas que apresentaram resultados positivos, permaneçam sendo bem executadas para continuidade dos resultados observados, entendeu-se necessária a análise de estruturas que fornecessem melhores condições à otimização das políticas de segurança pública, apontadas como meios eficientes na redução da insegurança pública.

Nesta tarefa, definiu-se que o sistema de segurança pública estrutura-se com base nas instituições policiais e, dentre estas, as polícias estaduais, principalmente a polícia ostensiva, são aquelas que possuem o maior campo de atuação no que diz respeito à prevenção criminal.

Neste sentido, foram analisados os modelos de policiamento que possibilitassem a melhor análise local da questão e, conseqüentemente, implementação das estratégias de prevenção mais adequadas. Assim, foi abordado o modelo de policiamento orientado à solução de problemas que utiliza a metodologia de identificação, análise, resposta ao problema e constante avaliação das medidas adotadas. Nesta seara, foram identificadas experiências que realmente reduziram os índices criminais e sentimento de segurança nas áreas em que foram implementadas.

Ato contínuo, o estudo focou o policiamento comunitário e as experiências realizadas no Brasil. Nestas, foi observado que, a despeito da grande propagação da filosofia comunitária em diversas regiões do país, com a realização, inclusive, de concursos e premiações, a prática parece ter se distanciado da proposição teórica, pois se priorizou a aproximação com a comunidade em detrimento da avaliação dos resultados em termos de prevenção criminal.

Em vista das distorções apresentadas pelas experiências realizadas acerca do policiamento comunitário, mantendo-se por base a imprescindível participação da sociedade no processo decisório sobre medidas destinadas à segurança pública, premissa inexistente no conceito de policiamento orientado à solução de problemas, concluiu-se pela necessidade de alteração na nomenclatura de policiamento comunitário para policiamento comunitário orientado à solução de problemas (PCOP).

A alteração da nomenclatura não visa uma mudança conceitual visto que no conceito atualmente adotado, a metodologia de orientação à solução do problema já está nele integrado. $\mathrm{O}$ objetivo foi o de readequar a prática ao modelo conceitual. 
A opção do modelo de policiamento comunitário, com a readequação da nomenclatura sugerida para policiamento comunitário orientado à solução de problemas representa o passo subseqüente à consolidação da tendência de abordagem local do problema da segurança pública por meio da participação decisória da comunidade e análise das informações do fenômeno criminal cada vez mais qualificadas em decorrência do implemento dos recursos tecnológicos.

Esta estrutura otimiza as políticas de segurança pública capazes de reduzir a insegurança pública, sem que sejam desrespeitados os princípios democráticos de direitos inerentes ao nosso ordenamento constitucional.

A idéia final é a adoção de políticas públicas de segurança com foco na garantia de direitos fundamentais a todos os integrantes do corpo social. De modo paralelo, no campo da prevenção criminal, o meio que se demonstra mais eficaz concretiza-se na implementação de políticas de segurança pública com a finalidade de melhor solucionar os problemas na área criminal e referentes ao medo do crime.

Se apenas com o direito à segurança pública os demais direitos poderão ser exercidos, não há antagonismos entre as políticas públicas de segurança e as políticas de segurança pública. Apesar das distinções acerca das finalidades de cada uma delas, há convergência para o objetivo único de concretização de uma sociedade em que seja garantido o direito à segurança pública e, por conseqüência, se permita o pleno exercício dos demais direitos fundamentais. 


\section{BIBLIOGRAFIA}

ABRAMOVAY, Miriam; e PINHEIRO, Leonardo Castro. Violência e Vulnerabilidade Social. In: Alicia Fraerman (Ed.). Inclusion Social y Desarrollo: Presente y futuro de la comunidad IberoAmericana. Madri: Comunica, 2003.

ADORNO, Sérgio. Violência: um retrato em branco e preto. São Paulo: Fundação para o Desenvolvimento da Educação, 1994.

AFONSO DA SILVA, José. Curso de Direito Constitucional Positivo. São Paulo: Malheiros, 1999.

AGNELO, Geraldo Majela. Raízes da violência e caminhos de paz. Folha de São Paulo, São Paulo, 01 ago. 2008. Tendências/Debates. Disponível em: $<$ http://www1.folha.uol.com.br/fsp/opiniao/fz0108200808.htm>. Acesso em: 29.11.2009.

ALVARENGA, Pedro Luís Bueno de. Videomonitorização de Locais Públicos e Policiamento Ostensivo - Aspectos Jurídicos e Operacionais, 2008. Monografia (Curso de Aperfeiçoamento de Oficiais) - Centro de Altos Estudos de Segurança "Cel PM Nelson Freire Terra", Polícia Militar do Estado de São Paulo, São Paulo.

AMNISTÍA INTERNACIONAL. BRASIL “Entran disparando”: La actuación policial en las comunidades socialmente exlcuídas. Trad. Editorial Amnistía Internacional (EDAI). Madrid: Aministía Internacional, 2005. Disponível em: <http:/www.amnesty.org/ es/library/asset/AMR19/025/2005/es/c81b1ed5-d49c-11dd-8a23-d58a49c0d652/amr19025 2005es.pdf>. Acesso em: 29.11.2009.

ANEMONE, Louis. A reforma da polícia. São Paulo: Instituto Fernand Braudel de Economia Mundial, n. 22, 1999, p. 2-8. Disponível em: $<$ http://www.braudel.org.br/publicacoes/bp/bp22_pt.pdf>. Disponível em: 29.11.2009.

ARAUJO DA SILVA, Eduardo. Crime Organizado: Procedimento Probatório. São Paulo: Atlas, 2003.

ARRUDA, Luiz Eduardo Pesce de. O líder policial e suas relações com os conselhos comunitários de segurança em São Paulo, A Força Policial. São Paulo: Polícia Militar do Estado de São Paulo, n. 16, out.-dez. 1997. 
ASSEMBLÉIA LEGISLATIVA DO ESPÍRITO SANTO. Pacto pela paz: pesquisas e subsídios. Vitória: Gráfica Espírito Santo, 2005.

BATTIBUGLI, Thaís. Segurança pública e cultura policial paulista (1946-1964). In: KOERNER, Andrei (Org.). História da justiça penal no Brasil. São Paulo: IBCCrim, 2006, p. 83-106.

BAUMAN, Zygmunt. Comunidade: a busca por segurança no mundo atual. Trad. Plínio Dentzien. Rio de Janeiro: Zahar, 2003.

BAYLEY, David H.; e SKILNICK, Jerome H. Nova polícia: Inovações nas polícias de seis cidades norte-americanas. Trad. Geraldo Gerson de Souza. São Paulo: EDUSP, 2001. (Série Polícia e Sociedade).

BECCARIA, Cesare. Dos delitos e das penas. Trad. Flório de Angelis. Bauru: EDIPRO, 2000. (Série Clássicos).

BELFORT, Andréa. Caminhos para o controle da violência. In: Visão Estratégica do Espírito Santo 2025. Benchmarking Internacional e com outras unidades da Federação. Atividade 10. Espírito Santo: Governo do Estado do Espírito Santo, 2006, p. 205-257.

BELLI, Benoni. Tolerância Zero e democracia no Brasil: visões da segurança pública na década de 90. São Paulo: Perspectiva, 2004.

BENATO, Luís Ricardo. Estratégia operacional voltada à prevenção de homicídios dolosos, utilizando técnicas policiais de manutenção da ordem pública na área do CPM, denominada operação quadrilátero: uma proposta, 2002. Monografia (Curso de Aperfeiçoamento de Oficiais) - Centro de Altos Estudos de Segurança "Cel PM Nelson Freire Terra”, Polícia Militar do Estado de São Paulo, São Paulo.

BERRÍO, Hernando León Londoño. Política Criminal del Estado en Colômbia, De Jure: Revista Jurídica do Ministério Público de Minas Gerais. Belo Horizonte: Ministério Público do Estado de Minas Gerais, n.9, jul.-dez. 2007, p. 13-49.

BEVILÁQUA, Clóvis. Teoria Geral do Direito Civil. Rio de Janeiro: Livraria Francisco Alves, 1929.

BEZERRA, Jorge Luiz. Segurança Pública: uma perspectiva político criminal à luz da teoria das janelas quebradas. São Paulo: Blucher Acadêmico, 2008.

BITENCOURT, Cezar Roberto. Manual de Direito Penal. São Paulo: Saraiva, 2002. 
BOUSQUAT, Marco Akerman Aylene. Mapas de risco de violência, São Paulo em Perspectiva. São Paulo: Fundação SEADE, v. 13, n. 4, oct.-dez. 1999. Disponível em: $<$ http://www.scielo.br/scielo.php?pid=S0102-88391999000400012\&script=sci_arttext $>$. Acesso em: 29.11.2009.

BRANDÃO, Ailton Araújo. Polícia comunitária: da prática à teoria, 2004. Monografia (Curso de Aperfeiçoamento de Oficiais) - Centro de Altos Estudos de Segurança "Cel PM Nelson Freire Terra”, Polícia Militar do Estado de São Paulo, São Paulo.

BRATTON, William J. e ANDREWS, Willian. What we've learned about policing. City Journal, New York: Manhattan Institute, Spring 1999. Disponível em: <http://www.cityjournal.org/html/9_2_what_weve_learned.html>. Acesso em: 29.11.2009.

BRATTON, Willian. Turnaround: how America's top Cop reversed the crime epidemic. New York/Toronto: Random House, 1998.

BRODEUR, Jean-Paul. Como reconhecer um bom policiamento: problemas e temas. Trad. Ana Luísa Amêndola Pinheiro. São Paulo: EDUSP, 2001. (Série Polícia e Sociedade).

BRUNO, Aníbal. Direito Penal. 2 ed. Rio de Janeiro: Forense, 1959.

BUCCI, Maria Paula Dallari. Políticas públicas e direito administrativo, Revista de Informação Legislativa. Brasília: Senado Federal, ano 34, n. 133, jan.-mar. 1997, p. 89-98. Disponível em: <http://www.senado.gov.br/web/cegraf/ril/Pdf/pdf_133/r133-10.PDF>. Acesso em: 29.11.2009.

CALDEIRA, Cesar. Segurança pública e seqüestros no Rio de Janeiro: 1995-96, Revista Brasileira de Ciências Criminais. São Paulo: IBCCrim, v. 5, n. 20, out.-dez. 1997, p. 193235.

CÂMARA DOS DEPUTADOS. Relatório da Comissão Parlamentar de inquérito destinada a investigar as organizações criminosas do Tráfico de armas. Brasília, 2006.

CAMARGO, Antonio Benedito Marangone. Mortes por causas violentas no Estado de São Paulo: a influência das agressões, São Paulo em Perspectiva. São Paulo: Fundação SEADE, v. 21, n.1, jan.-jun. 2007, p. 31-45. Disponível em: $<$ http://www.seade.gov.br/produtos/spp/v21n01/v21n01_03.pdf.>. Acesso em: 29.11.2009. CAMPOS, Marcelo da Silveira. Escolha racional e criminalidade: uma avaliação crítica do modelo, Revista da Seção Judiciária do Rio de Janeiro. Rio de Janeiro: Justiça Federal, n. 22, jun. 2008, p. 93-110. 
CANCIO MELIÁ, Manuel. Derecho penal del enemigo. Madrid: Civitas, 2003.

CANO, Ignácio. Perfil das armas vendidas a brasileiros no Paraguai. Rio de Janeiro: Instituto de Estudos da Religião, 2000. Disponível em: $<$ http://www.desarme.org/publique/media/Armas\%20vendidas\%20em\%20Paraguai.pdf $>$. Acesso em: 29.11.2009.

CANOTILHO, Joaquim José Gomes e MOREIRA, Vital. Constituição da República portuguesa anotada. Coimbra: Coimbra Editora, 2007. vol. I.

CANOTILHO, Joaquim José Gomes. Direito Constitucional e Teoria da Constituição. Coimbra: Almedina, 1999.

CAPEZ, Fernando. Curso de Processo Penal. São Paulo: Saraiva, 2002.

CARA, Daniel Tojeira. O papel dos grêmios estudantis na redução da violência: um breve relato da experiência do projeto grêmio em forma (2000-2003/2004). São Paulo: Instituto Sou da Paz, 2004. Disponível em: <http://www.soudapaz.org/Portals/0/Downloads/ Texto\%20Daniel\%20Cara.pdf>. Acesso em: 20.11.2009.

CARNELUTTI, Francesco. Metodologia do Direito. Trad. Frederico A. Paschoal. Campinas: Bookseller, 2002.

CARRANZA, Elías. Cárcel, seguridad pública y justicia penal: el modelo de derechos y deberes de las Naciones Unidas, Revista Ultima Ratio. Rio de Janeiro: Instituto Panamericano de Política Criminal, vol.1, n.1, 2007, p. 157-173.

CARVALHO, Orlando Adão. O Judiciário e a segurança pública, Revista do Instituto dos Advogados de Minas Gerais. Belo Horizonte: Instituto dos Advogados de Minas Gerais, n.13, 2007, p. 149-160.

CASTRO, Gustavo Almeida Paolinelli de. Segurança pública e controle social, Boletim do Instituto de Ciências Penais. Belo Horizonte: Instituto de Ciências Penais, v.4, n. 59, jul. 2005, p. 4-7.

CASTRO, Mônica S. Monteiro de; SILVA, Bráulio Figueiredo Alves da; ASSUNÇÃO Renato M.; FILHO, Cláudio Chaves Beato. Regionalização como estratégia para a definição de políticas públicas de controle de homicídios, Cadernos de Saúde Pública. Rio de Janeiro: Escola Nacional de Saúde Pública, Fundação Oswaldo Cruz, vol. 20, n. 5, set.out. 2004, p. 1269-1280. 
CENTRO DE ESTUDOS DE CRIMINALIDADE E SEGURANÇA PÚBLICA. Informativo. Belo Horizonte: Universidade Federal de Minas Gerais, ano 1, n. 5, fev. 2003. CERQUEIRA, Carlos Magno Nazareth (Org). Do patrulhamento ao policiamento comunitário. Rio de Janeiro: Freitas Bastos, 1999.

CHAVES, José Antonio Gomes. Análise Criminal: a prevenção do crime e contravenção, 2002. Monografia (Curso de Aperfeiçoamento de Oficiais) - ADESG/MT, Polícia Militar do Estado de Mato Grosso, Cuiabá.

COMISSÃO INTERAMERICANA DE DIREITOS HUMANOS - OEA. Relatório sobre a situação dos direitos humanos no Brasil. Washington: Organização dos Estados Americanos, 1997. Disponível em: <http://www.cidh.oas.org/countryrep/brazilport/indice.htm>. Acesso em: 29.11.2009.

COMPARATO, Fábio Konder. A polícia e a ética na segurança pública. In: MORAES, Bismael Batista de (Coord.). O papel da polícia no regime democrático. São Paulo: Mageart, 1996, p. 89-112.

. Ensaio sobre o juízo de constitucionalidade das políticas públicas, Revista dos Tribunais. São Paulo: Revista dos Tribunais, ano 86, vol. 737, mar. 1997, p. 11-22.

COSTA JÚNIOR, Orlando Taveirós. Proposta de Operacionalização dos Sistemas de Videomonitorização urbana como instrumento da PM para o Controle e Prevenção da Criminalidade, 2008. Monografia (Curso Superior de Polícia) - Centro de Altos Estudos de Segurança “Cel PM Nelson Freire Terra”, Polícia Militar do Estado de São Paulo, São Paulo.

COSTA JÚNIOR, Paulo José da. Comentários ao código penal. 5 ed. São Paulo: Saraiva, 1997.

COSTA, Helena Regina Lobo da. A Dignidade Humana: teorias de prevenção geral positiva. São Paulo: Revista dos Tribunais, 2008.

COUTINHO, Jacinto Nelson de Miranda. Segurança pública e o direito das vítimas, Revista de Estudos Criminais. Sapucaia do Sul: Notadez, vol. 2, n. 8, 2003, p. 136-144.

CRETELLA JÚNIOR, José. Dicionário de Direito Administrativo. Rio de Janeiro: Forense, 1978. 
CRIVELARI, Luiz Antonio. A polícia comunitária no Canadá: estudo de polícia como proposta subsidiária, 1999. Monografia (Curso Superior de Polícia) - Centro de Altos Estudos de Segurança "Cel PM Nelson Freire Terra", Polícia Militar do Estado de São Paulo, São Paulo.

CUBAS, Viviane de Oliveira. Segurança Privada: a expansão dos serviços de proteção e vigilância em São Paulo. São Paulo: Humanitas, 2005.

DE PLÁCIDO E SILVA, Oscar Joseph. Vocabulário Jurídico, Rio de Janeiro: Forense, 2001 .

DE VITTO, Renato Campos. Um crime para comentar e um samba para distrair, Boletim IBCCRIM. São Paulo: IBCCrim, vol. 16, n. 187, jun. 2008, p. 12.

DELAZARI, Luiz Fernando. Segurança pública e verbas irreais. O Estado de S.Paulo. São Paulo, 05 jan. 2005. Espaço Aberto, p. A-2. Disponível em: <http://www.tjm.sp.gov.br /Noticias/0105_Seguranca_publica_e_verbas_irreais.htm>. Acesso em: 29.11.2009.

DELLASOPPA, Emilio; BERCOVICH, Alicia M; e ARRIAGA Eduardo. Violência, direitos civis e demografia no Brasil na década de 80: o caso da área metropolitana do Rio de Janeiro, Revista Brasileira de Ciências Sociais. São Paulo: Associação Nacional de PósGraduação e Pesquisa em Ciências Sociais, vol. 14, n. 39, 1999, p. 155-176.

DIAS FILHO, Luiz. Integração de núcleos de defesa civil em escolas com as atividades de polícia comunitária, 2004. Monografia (Curso Superior da Polícia Militar do Estado de São Paulo) - Centro de Altos Estudos de Segurança “Cel PM Nelson Freire Terra”, Polícia Militar do Estado de São Paulo, São Paulo.

DIAS NETO, Theodomiro. Policiamento comunitário e controle sobre a polícia: a experiência norte-americana. São Paulo: IBCCrim, 2000.

. Segurança pública: um conceito a ser repensado, Boletim IBCCRIM. São Paulo: IBCCrim, n. 58, set. 1997, p. 12.

. Segurança urbana: o modelo da nova prevenção. São Paulo: Revista dos Tribunais, 2005.

DORNELLES, João Ricardo. Conflito e segurança: entre pombos e falcões. 2. ed. Rio de Janeiro: Lumen Juris, 2008. 
DOTTI, René Ariel. Bases e Alternativas para um sistema de penas. São Paulo: Revista dos Tribunais, 1998.

DOWDNEY, Luke. Crianças do Tráfico: um estudo de caso de crianças em violência armada organizada no Rio de Janeiro. Rio de Janeiro: Editora Sete Letras, 2004.

DUS, José Roberto. Segurança pública: tecnologia a serviço da integração das polícias e corpo de bombeiros, A força policial. São Paulo: Polícia Militar do Estado de São Paulo, n.31, jul.-set. 2001, p. 73-77.

FERNANDES, Antônio Scarance. Processo penal constitucional. São Paulo: Revista dos Tribunais, 2002.

FERNANDES, João Antônio da Costa e COSTA, Júlio Cézar. Policia Interativa: a democratização e universalização da Segurança Pública, 1998. Monografia (Curso de Aperfeiçoamento de Oficiais) - Universidade Federal do Espírito Santo, Polícia Militar do Estado do Espírito Santo, Vitória.

FERNANDES, Luís Fiães. As "novas” ameaças como instrumento de mutação do conceito "segurança”. In: VALENTE, Manuel Monteiro Guedes (Coord.). I Colóquio de Segurança Interna. Coimbra: Almedina, 2005, p. 123-149.

FERREIRA, Agnaldo Edson Ramos. A integração das polícias militar e civil do estado de Sergipe, 2003. Monografia (Curso Superior de Polícia) - Centro de Altos Estudos de Segurança "Cel PM Nelson Freire Terra", Polícia Militar do Estado de São Paulo, São Paulo.

FERREIRA, Carlos Adelmar. Alcance e relevância dos projetos comunitários de segurança desenvolvidos pela Polícia Militar em Ribeirão Preto entre 1982 e 1990, Revista do Centro Universitário Barão de Mauá, Ribeirão Preto: CBM, vol. 2, n. 1, jan.-jun. 2009, p. 54-67.

FERRI, Enrico. Princípios de direito criminal o criminoso e o crime. Campinas: Bookseller, 1996.

FIA/USP. Desenvolvimento e implantação de metodologia de monitoramento e avaliação do Plano de Integração e Acompanhamento de Programas Sociais de Prevenção de Violência - PIAPS/PNSP. São Paulo: Universidade de São Paulo, 2001.

FIGUEIREDO DIAS, Jorge de. Questões fundamentais do Direito Penal revisitadas. São Paulo: Revista dos Tribunais, 1999. 
FILOCRE, D’Aquino. Classificações de políticas de segurança pública, Revista Brasileira de Segurança Pública. São Paulo: Editora 5, ano 3, ago.-set. 2009, p. 146-157.

FONTES JUNIOR, João Bosco Araujo. Liberdades Fundamentais e Segurança Pública: do direito à imagem ao direito à intimidade - a garantia constitucional do estado de inocência. Rio de Janeiro: Lumen Juris, 2006.

FORTUNATO, Paulo Fernando. Segurança pública com novo sistema prisional, Boletim IBCCRIM, São Paulo: IBCCrim, n. 6, jul. 1993. p. 2.

FÓRUM METROPOLITANO DE SEGURANÇA PÚBLICA. Relatório $n^{\circ} 11$. São Paulo: Instituto São Paulo Contra a Violência, 2004.

. Relatório $n^{\circ}$ 13. São Paulo: Instituto São Paulo Contra a Violência, 2004. . Relatório $n^{\circ}$ 14. São Paulo: Instituto São Paulo Contra a Violência, 2004. . Relatório $n^{\circ}$ 15. São Paulo: Instituto São Paulo Contra a Violência, 2005.

FOUCAULT, Michel. Vigiar e punir. Trad. Ligia Vassalo. 8. ed. Petrópolis: Vozes, 1991.

GALEANO, Eduardo. El sacrifício de la justicia en los altares del orden. Los prisioneros. Revista de la asociacón de ciências penales de Costa Rica, Costa Rica: San José: Colégio de Abogados de Costa Rica e Unicef, año 12, n.14, dic. 1997. Disponível em: < http://www.cienciaspenales.org/REVISTA\%2014/galean14.htm>. Acesso em: 29.11.2009.

GARCIA, Basileu. Comentários ao Código de processo Penal. Rio de Janeiro: Forense, 1945. v. III.

. Instituições de Direito Penal. 3. ed. São Paulo: Max Limonad, 1956.

GAWRYSZWESKI, Vilma Pinheiro; KAHN, Túlio; e JORGE, Maria Helena Prado de Mello. Informações sobre homicídios e sua integração com o setor de saúde e segurança pública, Revista Saúde Pública. São Paulo: Faculdade de Saúde Pública da Universidade de São Paulo, vol. 39, n. 4, ago. 2005, p. 627-633.

GRAEFF, Beatriz Porfírio. O Policial Militar em tempos de mudança: ethos, conflitos e solidariedades na Polícia Militar do Estado de São Paulo, 2006. Dissertação (Mestrado em Antropologia Social) - Programa de Pós-Graduação em Antropologia Social, Universidade de Brasília, Brasília.

GREPPI, Wilson. O Conselho comunitário de segurança: proposta de padronização do papel do policial militar como membro nato, 1998. Monografia (Curso Superior de Polícia) 
- Centro de Altos Estudos de Segurança "Cel PM Nelson Freire Terra”, Polícia Militar do Estado de São Paulo, São Paulo.

HADDAD, Eneida Gonçalves de Macedo. Centros Integrados de Cidadania: Desenho e Implantação da Política Pública (2003/2005). Brasília: Ministério da Justiça, 2006.

HASSEMER, Winfried. Direito Penal: Fundamentos, Estrutura, Política. Trad. Adriana Beckmam Meirelles, et al. Porto Alegre: Sergio Antonio Fabris Editor, 2008.

HIRECHE, Gamil Foppel el. A Função da pena na visão de Claus Roxin. Rio de Janeiro: Forense, 2004.

HORTA, Cláudia Júlia Guimarães; AMARAL, Ernesto Friedrich de Lima; BRITO, Fausto. A urbanização recente no Brasil e as aglomerações metropolitanas. Belo Horizonte: CEDEPLAR - IUSSP, 2002.

HUGHES, Pedro Javier Aguerre. Segregação socioespacial e violência na cidade de São Paulo: referências para a formulação de políticas públicas. São Paulo Em Perspectiva, São Paulo: Fundação SEADE, vol.18, n. 4, 2004. p. 93-102. Disponível em: $<$ http://www.scielo.br/scielo.php?pid=S0102-88392004000400011\&script=sci_abstract $>$. Acesso em: 29.11.2009.

ILANUD (Org.). Das políticas de segurança pública às políticas públicas de segurança. São Paulo, 2002. . Polícia Comunitária: avaliando a experiência. São Paulo, 2000.

INSTITUTO BRASILEIRO DE CIÊNCIAS CRIMINAIS. Entre excessos e insuficiências perdem as instituições, Boletim IBCCRIM. São Paulo: IBCCrim, vol. 16, n. 190, set. 2008. p. 1 .

. Segurança pública e exclusão, Boletim IBCCRI. São Paulo: IBCCrim, vol. 15, n. 180 , nov. 2007. p. 1.

INSTITUTO DE ESTUDOS DA RELIGIÃO - NÚCLEO DE PESQUISA. Segurança Pública e Cidadania: a experiência de policiamento comunitário em Copacabana (19941995), Relatório final do monitoramento qualitativo. Rio de Janeiro, 1996.

INSTITUTO DE PESQUISA ECONÔMICA APLICADA. Diagnóstico e desempenho recente do programa nacional de segurança pública com cidadania, Brasil em desenvolvimento: Estado, planejamento e políticas públicas. Brasília, 2009, p. 761-778. 
INSTITUTO DE SEGURANÇA PÚBLICA. Relatório Final da Pesquisa de condições de vida e vitimização - 2007. Rio de Janeiro, 2009.

INSTITUTO SÃO PAULO CONTRA A VIOLÊNCIA. Projeto Abrace seu bairro Relatório Final. São Paulo, 2005.

. Relatório Anual 2000. São Paulo, 2001.

. Relatório Anual 2001. São Paulo, 2002.

. Relatório Geral Biênio 1998/1999. São Paulo, 2000.

. Relatório Geral Biênio 2002/2003. São Paulo, 2004.

INSTITUTO SOU DA PAZ. II Plano Municipal de Segurança de Diadem. São Paulo, 2005.

. Projeto São Paulo em paz. Diagnóstico da situação de violência - Distrito

Brasilândia. São Paulo, 2004. Disponível em: <http://www.soudapaz.org/ Portals/0/Downloads/resumo\%20diagnostico\%20brasilândia.pdf $>$. Acesso em: 20.11.2009.

JACKOBS, Günther; e MELIÁ, Manuel Cancio. Derecho penal del enemigo. 2 ed. Madrid: Civitas, 2006.

. Fundamentos do Direito Penal. Trad. André Luís Callegari. São Paulo:

Revista dos Tribunais, 2003.

JUCÁ, Roberta Laena Costa. O papel da sociedade na política de segurança pública, Jus Navigandi, Teresina, ano 7, n. 60, nov. 2002. Disponível em: $<$ http://jus2.uol.com.br/doutrina/texto.asp?id=3525>. Acesso em: 22.11.2009.

JUNQUEIRA, Gustavo Octaviano Diniz. Finalidades da pena. Barueri: Manole, 2004.

KAHN, Túlio. Armas de Fogo: argumentos para o debate, Boletim Conjuntura Criminal, 2002. Disponível em: <http://www.conjunturacriminal.com.br/boletins/html>. Acesso em: 15.11.2009.

. Cidades Blindadas: ensaios de criminologia. São Paulo: Sicurezza, 2002.

. Crime organizado, um inimigo desconhecido. Folha de São Paulo, São

Paulo, 13 jul. 2006, Folha Opinião. Disponível em: <http://arquivoetc.blogspot.com/2006 /07/crime-organizado-um-inimigo.html>. Acesso em: 10.10.2009. 
. Defesa nacional e segurança pública, Segurança e Defesa Nacional: da competição à cooperação regional. São Paulo: Fundação Memorial da América latina, out. 2006. Disponível em: <http://www.memorial.sp.gov.br/memorial/RssNoticiaDetalhe. do?noticiaId=788>. Acesso em: 29.11.2009

. Homicídios Dolosos em São Paulo, Estudos Criminológicos. São Paulo: Secretaria de Estado dos Negócios da Segurança Pública, n. 1, 2004, p. 12-29.

. O fetiche das estatísticas criminais. O Estado de S. Paulo, São Paulo, 19

fev. 2005. Disponível em: <http:/www.forumseguranca.org.br/artigos/o-fetiche-dasestatisticas-criminais>. Acesso em: 10.10.2009.

. Os custos da violência: quanto se gasta ou deixa de ganhar por causa do crime no estado de São Paulo, Revista São Paulo em Perspectiva. São Paulo: Fundação SEADE, vol. 23, n. 41, 1999, p. 42-8.

. Segurança Pública e trabalho policial no Brasil, Estudos Criminológicos.

São Paulo: Secretaria da Segurança Pública do Estado de São Paulo, n. 2, 2004.

Velha e Nova Polícia. Polícia e Politicas de Segurança Pública no Brasil Atual. São Paulo: Sicurezza, 2002.

KARAM, Maria Lucia. Segurança pública e processo de democratização, Discursos Sediciosos. Rio de Janeiro: Rio de Janeiro: Instituto Carioca de Criminologia/Revan, ano 3, n. 5 e 6,1998, p. $169-178$.

LABORATÓRIO DE HABITAÇÃO E ASSENTAMENTOS DA FACULDADE DE ARQUITETURA E URBANISMO DA UNIVERSIDADE DE SÃO PAULO. Curso de Capacitação e Desenvolvimento de Projetos. São Paulo, 2003.

- Programa Bairro Legal. Plano de Ação Habitacional e Urbano. Diagnóstico Jardim Ângela. São Paulo, 2003.

LAZZARINI, Álvaro. Estudos de Direito Administrativo. São Paulo: Revista dos Tribunais, 1996.

. O Corpo de Bombeiros Militar como instrumento de defesa da cidadania, $A$ Força Policial. São Paulo: Polícia Militar do Estado de São Paulo, n. 24, out-dez/1999, p. 13-28. 
LAZZARINI, Álvaro; TÁCITO, Caio; MOREIRA NETO, Diogo de Figueiredo; MEIRELLES, Hely Lopes; CRETELLA JÚNIOR, José; FERREIRA, Sérgio de Andréa. Direito Administrativo da Ordem pública. 2 ed. Rio de Janeiro: Forense, 1987.

LEMGRUBER, Julita. Uma boa experiência. O Globo, Rio de Janeiro, 22 dez. 2005. Disponível em: <http://www.ucamcesec.com.br/md_art_texto.php?cod_proj=56>. Acesso em: 29.11.2009.

LEMGRUBER, Julita. Verdades e mentiras sobre o sistema de justiça criminal, Revista CEJ. Brasília: Centro de Estudos Judiciários do Conselho da Justiça Federal, n. 15, set.dez. 2001, p. 12-29.

LEMGRUBER, Julita; MUSUMECI, Leonarda; RAMOS, Silvia. Porque é tão difícil implementar uma política de segurança pública?, Observatório da Cidadania. Rio de Janeiro, 2002, p. 46-54.

LEMOS, João Gonçalves de. Segurança pública: direito do cidadão x obrigação do estado. In: LEAL, César Barros; PIEDADE JÚNIOR, Heitor (Orgs.). Violência e vitimização: a face sombria do cotidiano. Belo Horizonte: Del Rey, 2001, p. 149-169.

LICO, Fátima Madalena de Campos. Juventude, violência e ação coletiva, 2009. Tese (Doutorado em Saúde Pública) - Faculdade de Saúde Pública, Universidade de São Paulo, São Paulo.

LIMA, Renato Sérgio de. Conflitos sociais e criminalidade urbana: uma análise dos homicídios cometidos no Município de São Paulo, 1998. Dissertação (Mestrado em Ciências Sociais) - Faculdade de Filosofia, Letras e Ciências Humanas, Universidade de São Paulo, São Paulo.

- Contando crimes e criminosos em São Paulo: uma sociologia das estatísticas produzidas e utilizadas entre 1871 e 2000, 2005. Tese (Doutorado em Ciências Sociais) - Faculdade de Filosofia, Letras e Ciências Humanas, Universidade de São Paulo, São Paulo.

LIRA, Pablo Silva. A Geografia do crime: construção e geoprocessamento do Índice de Violência Criminalizada - IVC no Município de Vitória - ES, 2007. Trabalho (Conclusão de Curso de Graduação) - Faculdade de Geografia, Universidade Federal do Espírito Santo, Vitória. 
LOPES, Edson. Política, segurança e criminalização de deslocados. São Paulo: Verve, 2008

MARIANO, Benedito Domingos. Por um novo modelo de polícia no Brasil: a inclusão dos municípios no sistema de segurança pública. São Paulo: Fundação Perseu Abramo, 2004.

MARQUES, José Frederico. Curso de Direito Penal. São Paulo: Saraiva, 1956. v. III.

MARQUES, Oswaldo Henrique Duek. Fundamentos da pena. São Paulo: Juarez de Oliveira, 2000.

MARTINS, Ives Gandra. Proibição legal para que empresas privadas especializadas em segurança, serviços de vigilância e de transporte de valores sejam constituídas por estrangeiros: constitucionalidade da vedação. Brasília: Escola da Advocacia Geral da União, ano I, n. 5, dez. 2000. Disponível em: <http://www.escola.agu.gov.br/revista/ Ano_I_dezembro_2000/05122000IvesProibLegal.pdf>. Acesso em: 27.11.2009.

MARTINS, João Henrique. Inovação e eficiência no controle do crime: uma análise estrutural de sistemas de justiça criminal, 2009. Dissertação (Mestrado em Ciências Políticas) - Faculdade de Filosofia, Letras e Ciências Humanas, Universidade de São Paulo, São Paulo.

MASSUNO, Elisabeth. Segurança pública no Japão e nos países da América Latina, em face do crime organizado, Revista ADPESP. São Paulo: Associação dos Delegados de Polícia do Estado de São Paulo, v.20, n.27, jun.1999, p. 15-19.

MÁXIMO, Alexandre Alves. A importância do mapeamento da criminalidade utilizandose tecnologia de informação geográfica para auxiliar a segurança pública no combate à violência, 2004. Dissertação (Mestrado em Engenharia de Produção) - Faculdade de Engenharia, Universidade Federal de Santa Catarina, Florianópolis.

MEDAUAR, Odete. Direito Administrativo Moderno. São Paulo: Revista dos Tribunais, 1998.

MELE, João Leonardo. Ordem pública: a intervenção das polícias ostensivas-preventivas na salvaguarda do meio-ambiente, 2008. Dissertação (Mestrado em Direito Ambiental) Universidade Católica de Santos, Santos. 
MELGAÇO, Lucas de Melo. A geografia do atrito. Dialética espacial e violência em Campinas, 2005. Dissertação (Mestrado em Geografia) - Faculdade de Filosofia Letras e Ciências Humanas, Universidade de São Paulo, São Paulo.

MENDES, Aderrone Vieira. Adaptação estratégica nas empresas transportadoras de valores: um estudo de caso na cidade de Goiânia-Goiás, 2002. Dissertação (Mestrado em Engenharia de Produção) - Faculdade de Engenharia de Produção, Universidade Federal de Santa Catarina, Florianópolis.

MESQUITA NETO, Paulo de. Policiamento Comunitário e Prevenção do Crime - a visão dos coronéis da Polícia Militar, Revista São Paulo em Perspectiva. São Paulo: Fundação SEADE, vol. 18, n.1, 2004, p. 103-110.

. Segurança, justiça e direitos humanos no Brasil. In: LIMA, Renato Sérgio de; PAULA, Liana (Orgs.). Segurança Pública e violência: o Estado está cumprindo seu papel? São Paulo: Contexto, 2006, p. 53-64.

MESQUITA NETO, Paulo de; SALLA, Fernando. A crise da segurança pública de Maio de 2006: um ano depois, Revista Ultima Ratio. Rio de Janeiro: Instituto Panamericano de Política Criminal, v.1, n.12007, p. 119-138.

MINAYO, Marília Cecília de Souza. Condicionantes Multifatoriais da violência e da qualidade de vida, Revista Virtual de Gestão de Iniciativas Sociais. Rio de Janeiro: UniSESI, n. 5, fev. 2006, p. 20-31.

MINGARDI, Guaracy. Tiras, gansos e trutas: segurança pública e polícia civil em São Paulo (1983-1990). Porto Alegre: Corag, 1992.

MINISTÉRIO DA JUSTIÇA. A segurança pública nas conferências brasileiras: Pesquisa sobre as propostas de segurança pública e temas afins, apresentadas nos relatórios finais e propostas emanadas das conferências nacionais realizadas entre 2003 e 2008. Brasília, 2008.

- Curso Nacional de Multiplicadores de Polícia Comunitária. Brasília: Secretaria Nacional da Segurança Pública, 2007.

. Guia para prevenção do crime e da violência nos municípios. Brasília:

Secretaria Nacional de Segurança Pública, 2005.

. Implantação do Sistema Único de Segurança Pública. Brasília: Secretaria Nacional de Segurança Pública, 2003-2005. 
Melhora percepção de segurança nos Territórios de Paz, aponta FGV.

Brasília, 15 set. 2009. Disponível em: <http://www.mj.gov.br/main.asp? $\mathrm{View}=\%$ 7B4E0605ED\%2DA923\%2D47D1\%2D8313\%2D91B5B639C26E\%7D\&Team= $\&$ params $=$ itemID $=\%$ 7B129A20BA \%2D5B10\%2D41B1\%2DA4C7\%2D85BBC3618D6C \%7D\%3B\&UIPartUID=\%7B2218FAF9\%2D5230\%2D431C\%2DA9E3\%2DE780D3E67D FE\%7D>. Acesso em: 29.11.2009.

MJ esclarece estudos do Ipea e da FGV sobre Pronasci. Brasília, 17 set. 2009. Disponível em: <2http://www.mj.gov.br/main.asp?View=\%7B4E0605ED\%2DA923\%2D4 ...artUID=\%7B2218FAF9\%2D5230\%2D431C\%2DA9E3\%2DE780D3E67>. Acesso em: 29.11. 2009 .

. Projeto Segurança Pública para o Brasil. Brasília: Secretaria Nacional de Segurança Pública, 2005.

Ranking dos Estados no controle de armas: análise preliminar quantitativa e qualitativa dos dados sobre armas de fogo apreendidas no Brasil. Brasília, 2009.

MIRABETE, Julio Fabbrini. Código de Processo Penal Interpretado. São Paulo: Atlas, 1995.

MIRANDA, Ana Paula Mendes de. Avaliação do Trabalho Policial nos registros de ocorrência e nos inquéritos referentes a homicídios dolosos consumados em áreas de delegacias legais. Relatório final de pesquisa do Concurso Nacional de pesquisas aplicadas em Segurança Pública e Justiça Criminal da Secretaria Nacional de Segurança Pública. Brasília, 2006.

MIRANDA, Ana Paula Mendes; NASCIMENTO, Nivio Caixeta do; MELLO, Kátia Sento-Sé. Segurança pública, segurança social e segurança humana. Rio de Janeiro: Instituto de Segurança Pública. vol. I, 2006.

MIRANDA, Orlando Pinto de. Programas de policiamento comunitário - Programas de capacitação voltados para as comunidades. Relatório final de pesquisa do Concurso Nacional de pesquisas aplicadas em Segurança Pública e Justiça Criminal da Secretaria Nacional de Segurança Pública. Natal - São Paulo, 2005.

MOORE, Mark. Policiamento Comunitário e Policiamento para a Solução de Problemas. In: MORRIS, Norval; TONRY, Michael (Orgs.). Policiamento Moderno. São Paulo: EDUSP, 2003, p. 115-176. 
MOREIRA NETO, de Figueiredo. Revisão doutrinária dos conceitos de ordem pública e segurança pública, Revista de informação legislativa. Brasília: Subsecretaria de Edições Técnicas do Senado Federal, ano 25, n. 97, jan.-mar.1998, p. 133- 154.

MOREIRA, Milton. Direcionamento do policiamento ostensivo do CPA - M/5 utilizandose dos dados da coordenadoria de análise e planejamento da secretaria de segurança pública (CAP-SSP), uma proposta, 1998. Monografia (Curso Superior da Polícia Militar do Estado de São Paulo) - Centro de Altos Estudos de Segurança "Cel PM Nelson Freire Terra”, Polícia Militar do Estado de São Paulo, São Paulo.

NASCIMENTO, Luís Felipe Zilli do. Violência e criminalidade em vilas e favelas dos grandes centros urbanos: um estudo de caso da Pedreira Prado Lopes, 2004. Dissertação (Mestrado em Ciências Sociais) - Faculdade de Ciências Sociais, Universidade Federal de Minas Gerais, Belo Horizonte.

NOGUEIRA JÚNIOR, Alberto. Segurança nacional, pública e nuclear e o direito à informação. Rio de Janeiro: UniverCidade, 2006.

NUVOLONE, Pietro. Forze armate e pubblica sicurezza, Rivista Italiana di Diritto Penale. Milano: Cacucci, v.5, 1952, p. 116-122.

OLIVEIRA JUNIOR, Emmanuel Silva Nunes de. Políticas públicas e estratégias de controle da ação letal das instituições policiais em São Paulo, 2004. Dissertação (Mestrado em Ciências Políticas) - Faculdade de Filosofia, Letras e Ciências Humanas, Universidade de São Paulo, São Paulo.

OLIVEIRA, Ana Sofia Schmidt de. Políticas Pública de Segurança e Políticas de Segurança Pública - da teoria à prática. In: ILANUD (Org.). Das políticas de segurança pública às políticas públicas de segurança. São Paulo, 2002, p. 57-76.

OLIVEIRA, Luciano. Não fale do Código de Hamurábi!: a pesquisa sócio-jurídica na pósgraduação em Direito. In: Sua excelência, o comissário e outros ensaios de sociologia jurídica. Rio de Janeiro: Letra Legal, 2004, pp. 137 - 167.

OLIVEIRA, Nilson Vieira. Policiamento Comunitário: Experiências no Brasil 2000-2002. São Paulo: Página Viva, 2002.

OLSÉN, Örjan, et al. Desemprego, rendimentos e crime: um estudo no município de São Paulo, Estudos Criminológicos. São Paulo: Secretaria de Estado dos Negócios da Segurança Pública, n.2, 2004, p. 4-73. 
PASCHOAL, Janaina Conceição. Constituição, Criminalização e Direito Penal Mínimo. São Paulo: Revista dos Tribunais, 2003.

. Direito Penal - Parte Geral. Barueri: Manole, 2003.

. Segurança Pública - Poder e Dever de todos. In: ILANUD (Org.). Das políticas de segurança pública às políticas públicas de segurança. São Paulo, 2002.

PAVARINI, Massimo. Segurança, criminalidade e Governo Democrático da Cidade: uma visão entre 'centro' e 'periferia', Revista Ultima Ratio. Rio de Janeiro: Instituto Panamericano de Política Criminal, v.1, n.1, 2007, p. 39-118.

PEDROSO FILHO, Otávio Ferreira. Propostas para redução do número de escoltas de adolescentes infratores em benefício do policiamento comunitário, 2003. Monografia (Curso Superior de Polícia) - Centro de Altos Estudos de Segurança "Cel PM Nelson Freire Terra”, Polícia Militar do Estado de São Paulo, São Paulo.

PEGORARO, Luiz. Politicas públicas municipais de prevenção na segurança pública uma visão dos conselhos de segurança de bairros, 2002. Monografia (Curso Superior da Polícia Militar do Estado de São Paulo) - Centro de Altos Estudos de Segurança "Cel PM Nelson Freire Terra", Polícia Militar do Estado de São Paulo, São Paulo.

PEIXOTO, Betânia Totino; ANDRADE, Mônica Viegas; AZEVEDO João Pedro. Avaliação do Programa "Fica Vivo" no Município de Belo Horizonte, Anais do XXXV Encontro Nacional de Economia. Belo Horizonte: ANPEC - Associação Nacional dos Centros de Pós-graduação em Economia, 2007. Disponível em: $<$ http://www.anpec.org.br/encontro2007/artigos/A07A165.pdf $>$. Acesso em: 29.11.2009.

PIERRO JÚNIOR, Miguel Thomaz di. O efetivo exercício da segurança pública, 2008. Tese (Doutorado em Direito do Estado), Faculdade de Direito, Universidade de São Paulo, São Paulo.

PINHO, Pedro Paulo Pontes. Segurança pública: equívoco. O Globo, Rio de Janeiro, 13 jan. 2005. Tema em discussão, p. 6.

PITOMBO, Antonio Sergio Altieri de Moraes. A fatal desorganização do Estado: crime organizado não é único causador da insegurança pública. Rio de Janeiro: Associação Internacional de Direito Penal, mai. 2006. Disponível em: <http://www.aidpbrasil.org.br/ A\%20FATAL\%20DESORGANIZAÇÃO\%20DO\%20ESTADO\%20-\%20Antonio\%20Pito mbo.pdf $>$. Acesso em: 29.11.2009. 
POLÍCIA MILITAR DO ESTADO DE SÃO PAULO; AGÊNCIA DE COOPERAÇÃO INTERNACIONAL DO JAPÃO. Cooperação Técnica Japonesa para o Projeto de Policiamento Comunitário. São Paulo, 2004.

PROGRAMA GESTÃO PÚBLICA E CIDADANIA. Vinte Experiências de Gestão Pública e Cidadania 2000. Finalistas do Ciclo de Premiação 2000. São Paulo, 2001.

PUTNAM, Robert. Comunidade e Democracia: a experiência da Itália moderna. Rio de Janeiro: FGV Editora, 1993.

QUEIROZ, Raphael Augusto Sofiati de. Direito público \& segurança pública: ensaios e pareceres. Rio de Janeiro: Lumen Juris, 2001.

RAMOS, João Gualberto Garcez. A Sanção administrativa aplicada pelas agências reguladoras: instrumentos de prevenção da criminalidade econômica, 2005. Dissertação (Mestrado em Direito do Estado) - Faculdade de Direito, Universidade Federal do Paraná, Curitiba.

REALE JÚNIOR, Miguel. Instituições de Direito Penal: Parte Geral, Rio de Janeiro: Forense, 2003, v. II. . Instituições de Direito Penal: Parte Geral. Rio de Janeiro: Forense, 2002, v. I.

REALE, Miguel. O Estado Democrático de Direito e o conflito de ideologia. 2 ed. São Paulo: Saraiva, 1999.

REZENDE, Renato de Almeida. Geoprocessamento e sua e eficácia na prevenção da criminalidade na cidade de Botucatu, 2002. Monografia (Curso Superior da Polícia Militar do Estado de São Paulo)- Centro de Altos Estudos de Segurança "Cel PM Nelson Freire Terra", Polícia Militar do Estado de São Paulo, São Paulo.

RICO, José Maria. El Rol Policial. In: DAMMERT, Lúcia; PALSEN, Gustavo (Eds.). Ciudad y seguridade en América Latina. Santiago de Chile: Flacso/RED 14, 2005, p. 1745.

RODRIGUES, Alberto Silveira. A rota na prevenção especializada ao roubo de cargas no Município de São Paulo, 1996. Monografia (Curso Superior da Polícia Militar do Estado de São Paulo) - Centro de Altos Estudos de Segurança "Cel PM Nelson Freire Terra", Polícia Militar do Estado de São Paulo, São Paulo. 
RODRIGUES, Anabela Maria Pinto Miranda. O tribunal de justiça das comunidades européias no espaço de liberdade, de segurança e de justiça - A caminhar se faz o caminho, Revista Portuguesa de Ciência Criminal. Coimbra: Coimbra Editora, v.17, n.3, jul.-set. 2007, p. 387-413.

RODRIGUES, Cláudia Gouthier de Carvalho. Redução do número de homicídios no Aglomerado Morro das Pedras após a implantação do Programa Fica Vivo, 2007. Monografia (Curso pós-graduação em Direito lato sensu) - Escola Superior Dom Helder Câmara, Belo Horizonte.

RODRIGUES, João Gaspar. Segurança Pública e Comunidade. Porto Alegre: Sergio Antonio Fabris Editor, 2009.

RODRIGUES, Wagner. O serviço “disque - denúncia” e sua relação com a prevenção criminal, 2003. Monografia (Curso Superior da Polícia Militar do Estado de São Paulo) Centro de Altos Estudos de Segurança “Cel PM Nelson Freire Terra”, Polícia Militar do Estado de São Paulo, São Paulo.

RODRIGUES, Wanderley Pinto. Motivação no policiamento comunitário: um estudo, 2002. Monografia (Curso Superior da Polícia Militar do Estado de São Paulo)- Centro de Altos Estudos de Segurança “Cel PM Nelson Freire Terra”, Polícia Militar do Estado de São Paulo, São Paulo.

ROLIM, Marcos. A Síndrome da Rainha Vermelha: policiamento e segurança pública no século XXI. 2 ed. Rio de Janeiro: Jorge Zahar, 2009. . Justiça restaurativa e segurança pública, Revista $I O B$ de Direito Penal e Processual Penal. Porto Alegre: IOB, v.9, n.49, abr.-mai. 2008, p. 159-177.

ROMANO, Oduvaldo. Interligação da polícia comunitária com tolerância zero no combate à criminalidade em Caraguatatuba-PMESP, 1999. Monografia (Curso Superior da Polícia Militar do Estado de São Paulo) - Centro de Altos Estudos de Segurança "Cel PM Nelson Freire Terra", Polícia Militar do Estado de São Paulo, São Paulo.

ROSENBAUM, Dennis. A mudança no papel da polícia: avaliando a transição para policiamento comunitário. In: BRODEUR, Jean-Paul. Como reconhecer um bom policiamento. Trad. Ana Luísa Amêndola Pinheiro. São Paulo: EDUSP, 2002, p. 27-56.

ROXIN, Claus. Problemas fundamentais de Direito Penal. $3^{\mathrm{a}}$ ed. portuguesa. Trad. Ana Paula dos Santos et alli. Lisboa: Veja, 1998. 
SABADELL, Ana Lúcia. Segurança pública, prevenção e movimento feminista: uma aproximação ao caso alemão, Revista Brasileira de Ciências Criminais. São Paulo: IBCCrim, v. 8, n. 29, jan.-mar. 2000, p. 53-67.

SAIN, Marcelo Fabían; GAMES, Nicolás Rodríguez. La policía comunitaria en América Latina - Experiencias y proyecciones, Estudios Temáticos. Panamá: PNUD, 2004.

SANTIN, Valter Foleto. Controle Judicial da Segurança pública: eficiência do serviço na prevenção e repressão do crime. São Paulo: Revista dos Tribunais, 2004.

SARLET, Ingo Wolfgang. A Eficácia dos direitos fundamentais. Porto Alegre: Livraria do Advogado, 1999.

SCHNEIDER, Alexandre Alves. Determinantes da Criminalidade na Região Metropolitana de São Paulo, 2005. Dissertação (Mestrado em Administração Pública e Governo) - Escola de Administração de Empresas de São Paulo, Fundação Getulio Vargas.

SEBRAE. Ações e iniciativas de valorização do desenvolvimento local, Relatório final. São Paulo, v.1, 2004.

SECRETARIA DA ADMINISTRAÇÃO E DOS RECURSOS HUMANOS DO GOVERNO DO ESTADO DO RIO GRANDE DO SUL. Polícia: desafio da democracia brasileira, Porto Alegre, 2002.

SECRETARIA DA SEGURANÇA PÚBLICA DO ESTADO DE SÃO PAULO. Estatística de Criminalidade. Manual de Interpretação. São Paulo: Coordenadoria de Análise e Planejamento, 2005.

- Estudos Criminológicos. São Paulo: Coordenadoria de Análise e Planejamento, n. 1, 2004.

- Estudos Criminológicos. São Paulo: Coordenadoria de Análise e Planejamento, n. 2, 2004.

- Estudos Criminológicos. São Paulo: Coordenadoria de Análise e Planejamento, n. 3, 2005.

- Estudos Criminológicos. São Paulo: Coordenadoria de Análise e Planejamento, n. 7, 2008.

. O Papel dos Municípios na Segurança Pública. Estudos Criminológicos.

São Paulo: Coordenadoria de Análise e Planejamento, n. 4, 2005. 
SECRETARIA MUNICIPAL DE PLANEJAMENTO DO MUNICÍPIO DE SÃO PAULO.

Olhar São Paulo: Violência e Criminalidade. São Paulo: Prefeitura do Município de São Paulo, 2008. Disponível em: <http://sempla.prefeitura.sp.gov.br/mm/criminalidade/>. Acesso em: 29.11.2009.

SENTO-SÉ, João Trajano. Prevenção da Violência: o papel das cidades. Rio de Janeiro: Civilização Brasileira, 2005.

SERRÄO, Osvaldo. Segurança pública, imprensa e direitos individuais, Boletim IBCCRIM. São Paulo: IBCCrim, n.57, ago.1997, p. 8.

SERVILHA, Élson Roney. As áreas de preservação permanente dos cursos d'água urbanos para a ordem pública: Município de Campinas/SP, 2003. Dissertação (Mestrado em Engenharia Civil) - Faculdade de Engenharia Civil, Universidade Estadual de Campinas, Campinas.

SHECAIRA, Sérgio Salomão. Tolerância Zero, Revista Internacional de Direito e Cidadania. São Paulo: IEDC, n.5, out. 2009, p. 165-176.

SHECAIRA, Sérgio Salomão; CORRÊA JÚNIOR, Alceu. Pena e constituição. São Paulo: Revista dos Tribunais, 1995.

SILVA, Armando Leonardo Linhares A. F.. A conversão do conhecimento na prestação do serviço policial de prevenção ao crime: análise da construção do conhecimento no contexto de redes interorganizacionais configuradao através do GEPAR da Pedreira Prado Lopes, 2009. Dissertação (Mestrado em Administração Pública) - Fundação João Pinheiro, Escola de Governo Professor Paulo Neves de Carvalho, Belo Horizonte.

SILVA, Carlos Amaral da. A criação de um centro integrado de operações entre os órgãos do sistema de segurança pública, 2003. Monografia (Curso Superior da Polícia Militar do Estado de São Paulo) - Centro de Altos Estudos de Segurança "Cel PM Nelson Freire Terra”, Polícia Militar do Estado de São Paulo, São Paulo.

SILVA, Gilberto Tardochi da. Interfaces possíveis entre o programa de policiamento comunitário e órgãos públicos e privados - estudo de caso da região do Jardim Ranieri, 2006. Monografia (Curso de Aperfeiçoamento de Oficiais da Polícia Militar do Estado de São Paulo) - Centro de Altos Estudos de Segurança "Cel PM Nelson Freire Terra”, Polícia Militar do Estado de São Paulo, São Paulo. 
SILVA, Luís Virgílio Afonso da. O conteúdo essencial dos Direitos Fundamentais e a eficácia das normas constitucionais, Revista de Direito do Estado. Rio de Janeiro: Renovar, ano 1, n. 4, out.-dez. 2006, p. 23-51.

. O proporcional e o razoável, Revista dos Tribunais. São Paulo: Revista dos Tribunais, ano 91, v. 798, abr. 2002, p. 23-50.

. Princípios e regras: mitos e equívocos acerca de uma distinção, Revista Latino-Americana de Estudos Constitucionais. Belo Horizonte: Del Rey, n.1, 2003, p. 607628.

SILVA FILHO, José Vicente da. A Segurança Pública: o que falta fazer?. In: XVIII Fórum Nacional Porque o Brasil não é um país de alto crescimento? Rio de Janeiro: Instituto Nacional de Altos Estudos, 2006.

SILVEIRA, Andréa Maria. Prevenindo homicídios: Avaliação do Programa Fica Vivo no Morro das Pedras em Belo Horizonte, 2007. Tese (Doutorado em Ciências Humanas) Faculdade de Filosofia e Ciências Humanas, Universidade Federal de Minas Gerais, Belo Horizonte.

SIRVINSKAS, Luís Paulo. Segurança pública: um problema policial ou político?, Boletim IBCCRIM. São Paulo: IBCCrim, v.14, n.164, jul. 2006, p. 10.

SKOLNICK, Jerome; BAYLEY, David. Policiamento Comunitário: Questões e Práticas através do mundo. Trad. Ana Luísa Amêndola Pinheiro. São Paulo: EDUSP, 2006.

SOARES, Luiz Eduardo. A Política Nacional de Segurança pública: histórico, dilemas e perspectiva, Estudos Avançados. São Paulo: USP, n.61, 2007, p. 77-98.

. Meu casaco de general: 500 dias no fronte da segurança pública do Rio de Janeiro. São Paulo: Companhia das Letras, 2000.

. Novas políticas de segurança pública, Estudos Avançados. São Paulo: USP, v. 17, n. 47,2006, p. $75-96$.

. Segurança pública: presente e futuro, Estudos Avançados. São Paulo: USP, v. 20, n. 56,2006 , p. 91-106.

SOUZA NETO, Cláudio Pereira de. A segurança pública na Constituição Federal de 1988: Conceituação constitucionalmente adequada, competências federativas e órgãos de execução das políticas, Revista de Atualidades Jurídicas da OAB. Brasília: OAB Editora, 
mar.-abr. 2008. Disponível em: <http://www.oab.org.br/oabeditora/users/ revista/1205505974174218181901.pdf>. Disponível em: 29.11.2009.

SOUZA, Benedito Roque de. A integração policial entre os próprios órgãos, com os demais da administração pública e com o terceiro setor, 2001. Monografia (Curso Superior da Polícia Militar do Estado de São Paulo) - Centro de Altos Estudos de Segurança "Cel PM Nelson Freire Terra", Polícia Militar do Estado de São Paulo, São Paulo.

SOUZA, Bruno César Grossi de. Orçamento e segurança pública um estudo de caso do fundo nacional de segurança pública, 2004. Monografia (Pós-graduação latu sensu) Núcleo de Pesquisa em Políticas Públicas, Universidade de Brasília, Brasília.

SOUZA, Diego Fajardo Maranha Leão de. Segredo de Estado e direitos fundamentais. In: FERNANDES, Antonio Scarance; ALMEIDA, José Raul Gavião de; MORAES, Mauricio Zanoide de (Coords.). Sigilo no processo penal: eficiência e garantismo. São Paulo: Revista dos Tribunais, 2008, p. 267-298.

SOUZA, Kathie Njaine Edinilsa; SOUZA, Ramos de Maria Cecília de Minayo; ASSIS, Simone Gonçalves de. A produção da (des)informação sobre violência: análise de uma prática discriminatória, Cadernos de Saúde Pública. Rio de Janeiro: Escola Nacional de Saúde Pública, Fundação Oswaldo Cruz, v.13, n.3, jul-set/1997, pp. 405-414.

SOUZA, Luís Antônio Francisco de. Segurança pública, polícia e violência policial: perspectivas diante do endurecimento policial, Revista Brasileira de Ciências Criminais. São Paulo: IBCCrim, v.12, n.51, nov.-dez.2004, p. 253-288.

SULOCKI, Victoria-Amália de Barros Carvalho G. de. Segurança Pública e Democracia: aspectos constitucionais das políticas públicas de segurança. Rio de Janeiro: Lúmen Juris, 2007.

TISCORNIA, Sofia. Os novos modelos de segurança pública na América Latina, Segurança pública como tarefa do Estado e da Sociedade. Debates, n. 18, São Paulo: Centro de Estudos Fundação Konrad-Adenauer-Stiftung, 1998, p. 87-100.

TOLEDO JÚNIOR, Theseo Darcy Bueno de. Paz para quem tem carro: uso de programa de policiamento preventivo ostensivo para a diminuição dos furtos de veículos no Municipio de Mogi das Cruzes, 2008. Monografia (Curso de Especialização em Políticas 
de Gestão em Segurança Pública) - Pontifica Universidade Católica de São Paulo, São Paulo.

TORRIGO, Miriam. Aplicação dos sistemas de informação geográfica (SIG) no estudo da violência no ambiente urbano: o caso do Municipio de São Paulo-SP, 2005. Dissertação (Mestrado em Saúde Pública), Faculdade de Saúde Pública, Universidade de São Paulo, São Paulo.

TOURINHO FILHO, Fernando da Costa. Processo Penal. 20 ed. São Paulo: Saraiva, 1998. v. III.

TROJANOWICZ, Robert; BUCQUEROUX, Bonnie. Policiamento comunitário: como começar. Trad. Mina Seinfeld de Carakushansky. Rio de Janeiro: Polícia Militar do Estado do Rio de Janeiro, 1994.

UNESCO. Mapa da violência IV: os jovens do Brasil. Brasília, 2004.

. Politicas públicas de/para/com as juventudes. Brasília, 2004.

. Violências nas escolas - Versão resumida. Brasília, 2002.

UNIVERSIDADE CÂNDIDO MENDES - CESeC; INSTITO DE PESQUISA APLICADA. Criminalidade, Violência e Segurança Pública no Brasil: uma discussão sobre as Bases de Dados e Questões Metodológicas, $1^{\circ}$ Encontro: Conceituação do Sistema de Justiça Criminal Crime e Relato I: as Bases de dados Policiais. Rio de Janeiro, 2000.

UNIVERSIDADE CÂNDIDO MENDES. Base nacional de estatísticas criminais análise e avaliação. Rio de Janeiro, 2003.

UNIVERSIDADE DE SÃO PAULO. O policiamento que a sociedade deseja. São Paulo: Núcleo de Estudos da Violência, 2003.

VARGAS, Joana Domingues. Crimes sexuais e sistema de justiça. São Paulo: IBCCrim, 2000 .

VILARDI, Iara Ferfoglia Gomes Dias. Súmula Vinculante: razões e conseqüências de sua implementação no sistema de direito brasileiro, 2008. Dissertação (Mestrado em Filosofia e Teoria Geral do Direito) - Faculdade de Direito, Universidade de São Paulo, São Paulo.

WACQUANT Loïc. As prisões da miséria. Trad. André Telles. Rio de Janeiro: Jorge Zahar, 2001. 
. A ascensão do Estado penal nos EUA, Discursos Sediciosos: Crime, Direito e Sociedade. Rio de Janeiro: Instituto Carioca de Criminologia/Revan, ano 7, n. 11, 2002, p. $15-41$.

WILSON, James Q. e KELLING, George L.. Broken Windows: the police and neighborhood safety. Atlantic Montly (Digital edition), 1982. Disponível em: $<$ http://www.theatlantic.com/doc/198203/broken-windows>. Acesso em: 29.11.2009.

XAVIER, Laércio Noronha. Políticas públicas de segurança urbana, Diário do Nordeste, 2008. Disponível em: <http://diariodonordeste.globo.com/materia.asp?codigo=407829>. Disponível em: 29.11.2009.

XAVIER, Lêniton Matos. Programa de incentivo à produtividade na atividade-fim, 1998. Monografia (Curso Superior da Polícia Militar do Estado de São Paulo) - Centro de Altos Estudos de Segurança "Cel PM Nelson Freire Terra”, Polícia Militar do Estado de São Paulo, São Paulo, 1998.

ZAFFARONI, Eugenio Raúl. Manual de Direito Penal Brasileiro - Parte Geral. São Paulo: Revista dos Tribunais, 2002. . O inimigo no direito penal. Rio de Janeiro: Revan, 2007.

ZANETIC, André. A questão da segurança privada: estudo do marco regulatório dos serviços particulares de segurança, 2005. Dissertação (Mestrado em Ciência Política) Faculdade de Filosofia, Letras e Ciências Humanas, Universidade de São Paulo, São Paulo. 


\section{RESUMO}

O trabalho tem por objetivo verificar se há argumentos e estudos que comprovem que a implementação de políticas públicas de segurança e/ou políticas de segurança pública foram responsáveis por uma melhora significativa na segurança pública. Esta é a hipótese testada. Inicialmente são estabelecidos os limites conceituais sobre as diferentes acepções do termo segurança pública e os meios de mensuração desta, além de suas principais matrizes e agentes responsáveis pela sua preservação, tudo com o objetivo de tornar possível identificar e a qualificar como positivos ou negativos os impactos mensurados. Em um segundo momento, por meio do método dialético, são apresentados e discutidos argumentos sobre as condicionantes ou fatores de risco individuais e estruturais que se relacionam com as práticas criminosas e com o sentimento de segurança pública por parte da comunidade, além da tendência de abordagem local da questão como meio de resolução dos problemas enfrentados. Posteriormente, é analisada a distinção entre políticas públicas de segurança e políticas de segurança pública, diferenciando-se as iniciativas que devem ser abrigadas por cada expressão em conjunto com a avaliação de experiências e projetos que foram implementados com o objetivo de alcançar resultados positivos na prevenção criminal e percepção deste resultado pela sociedade. Durante a análise dos projetos é relatado o estudo de caso realizado, consistente na análise de uma política pública de segurança ("Praças da Paz") e de uma política de segurança pública (videomonitorização) com a finalidade de testar, juntamente com os demais projetos sobre os quais já haviam estudos elaborados, a hipótese do presente trabalho. A hipótese testada é parcialmente demonstrada visto que, apesar da imprescindibildade da adoção de políticas públicas de segurança, que visam garantir direitos fundamentais em um espectro mais abrangente do que o direito à segurança pública, os resultados positivos destas políticas resumiram-se, em regra, ao aspecto subjetivo da segurança pública, sendo que alterações significativas no que diz respeito ao aspecto objetivo (prevenção criminal) só foram constatadas em três das quatro áreas no estudo de caso referente ao programa de videomonitorização (política de segurança pública). Em virtude desta demonstração parcial da hipótese, que indica que as políticas de segurança pública podem reduzir tanto os índices criminais quanto o "medo do crime", aliada à constatação de que o ordenamento constitucional estabelece as instituições policiais como as principais responsáveis pela prestação do serviço de segurança pública, são discutidos modelos de policiamento que possibilitem a garantia de uma eficiente implementação das políticas de segurança pública, sendo apresentado o 
policiamento comunitário orientado à solução de problemas (PCOP), inclusive com a sugestão de alteração da nomenclatura para melhor transmissão de seus objetivos, como modelo capaz de, em respeito à necessidade de participação decisória da sociedade, diagnosticar, implementar, monitorar e avaliar as políticas de segurança pública como meio de redução da insegurança pública.

Palavras-chave: delito, política pública de segurança, política de segurança pública, segurança pública, prevenção, policiamento comunitário, policiamento orientado à solução de problemas. 


\section{RIASSUNTO}

L'obiettivo di questo studio è quello di verificare se vi sono argomenti e studi che comprovino che l'implementazione di politiche pubbliche di sicurezza e/o politiche di sicurezza pubblica furono le responsabili per un miglioramento significativo nella sicurezza pubblica. Questa è l'ipotesi sperimentata. Inizialmente vengono stabiliti i limiti concettuali sulle differenti accezioni del termine sicurezza pubblica e i mezzi per misurarla, oltre alle sue principali matrici e gli agenti responsabili per la sua preservazione, tutto con l'obiettivo di rendere possibile identificare e qualificare come positivi o negativi gli impatti misurati. In un secondo momento, attraverso il metodo dialettico, sono presentati e discussi argomenti sulle condizionanti o $\mathrm{i}$ fattori di rischio individuali e strutturali che si collegano con le pratiche criminali e con il sentimento di sicurezza pubblica percepita dalla comunità, oltre alla tendenza di approccio locale della questione come mezzo di risoluzione dei problemi affrontati. Successivamente, viene analizzata la distinzione tra le politiche pubbliche di sicurezza e le politiche di sicurezza pubblica, differenziando le iniziative che devono essere incluse da ognuna delle espressioni insieme con la valutazione di esperienze e progetti che sono stati implementati con l'obiettivo di raggiungere risultati positivi nella prevenzione criminale e la percezione di questo risultato dalla società. Durante l'analisi dei progetti viene riportato lo studio di un case realizzato, consistente nell'analisi di una politica pubblica di sicurezza ("Piazze della Pace") e di una politica di sicurezza pubblica (videomonitoraggio) allo scopo di testare, insieme agli altri progetti rispetto ai quali vi erano già studi elaborati, l'ipotesi del presente studio. L'ipotesi sperimentata è parzialmente dimostrata, visto che, malgrado l'imprescindibilità dell'adozione di politiche pubbliche di sicurezza, che hanno come socpo assicurare i diritti fondamentali in uno spettro più ampio del diritto alla sicurezza pubblica, i risultati positivi di queste politiche si sono riassunte fondamentalmente all'aspetto soggettivo della sicurezza pubblica, e alterazioni significative per quanto riguarda l'aspetto obiettivo (prevenzione criminale) sono state constatate soltanto su tre delle quattro aree nello studio del caso riferente al programma di videomonitoraggio (politica di sicurezza pubblica). In virtù di questa dimostrazione parziale dell'ipotesi, che indica che le politiche di sicurezza pubblica possono ridurre sia gli indici criminali che la "paura del crimine", alleata alla constatazione che l'ordinamento costituzionale stabilisce le istituzioni poliziesche come le principali responsabili per la prestazione di servizio di sicurezza pubblica, vengono 
discussi modelli di poliziamento comunitario orientato alla soluzione di problemi (PCOP), compreso il suggerimento di alterazione della nomenclatura per una migliore trasmissione dei suoi obiettivi, come modello capace di, rispettando la necessità della partecipazione decisoria della società, diagnosticare, implementare, monitorare e valutare le politiche di sicurezza pubblica come un mezzo di riduzione dell'insicurezza pubblica.

Parole chiave: reato, politica pubblica di sicurezza, politica di sicurezza pubblica, sicurezza publica, prevenzione, poliziamento comunitario, poliziamento orientatto alla soluzione di problemi. 